\title{
Hydrogen Sulfide Promotes Nodulation and Nitrogen Fixation in Soybean-Rhizobia Symbiotic System
}

\author{
Hang Zou, ${ }^{1,2}$ Ni-Na Zhang, ${ }^{3}$ Qing Pan,, ${ }^{1,2}$ Jian-Hua Zhang, ${ }^{4,5}$ Juan Chen, ${ }^{1,3,4,+}$ and Ge-Hong Wei ${ }^{1,2, \dagger}$ \\ ${ }^{1}$ State Key Laboratory of Crop Stress Biology in Arid Areas, College of Life Sciences, Northwest A\&F University, Yangling, \\ Shaanxi 712100, PR China \\ ${ }^{2}$ Shaanxi Key Laboratory of Agricultural and Environmental Microbiology, Yangling, Shaanxi 712100, PR China \\ ${ }^{3}$ State Key Laboratory of Soil Erosion and Dryland Farming on the Loess Plateau, Northwest A\&F University, Yangling, Shaanxi \\ 712100, P.R. China \\ ${ }^{4}$ School of Life Sciences and State Key Laboratory of Agrobiotechnology, the Chinese University of Hong Kong, Hong Kong \\ ${ }^{5}$ Department of Biology, Hong Kong Baptist University, Hong Kong
}

Accepted 20 February 2019.

\begin{abstract}
The rhizobium-legume symbiotic system is crucial for nitrogen cycle balance in agriculture. Hydrogen sulfide $\left(\mathrm{H}_{2} \mathrm{~S}\right)$, a gaseous signaling molecule, may regulate various physiological processes in plants. However, whether $\mathrm{H}_{2} \mathrm{~S}$ has regulatory effect in this symbiotic system remains unknown. Herein, we investigated the possible role of $\mathrm{H}_{2} \mathrm{~S}$ in the symbiosis between soybean (Glycine max) and rhizobium (Sinorhizobium fredii). Our results demonstrated that an exogenous $\mathrm{H}_{2} \mathrm{~S}$ donor (sodium hydrosulfide [NaHS]) treatment promoted soybean growth, nodulation, and nitrogenase (Nase) activity. Western blotting analysis revealed that the abundance of Nase component nifH was increased by NaHS treatment in nodules. Quantitative real-time polymerase chain reaction data showed that NaHS treatment upregulated the expressions of symbiosis-related genes $\operatorname{nod} A, \operatorname{nod} C$, and $\operatorname{nod} D$ of $S$. fredii. In addition, expression of soybean nodulation marker genes, including early nodulin 40 (GmENOD40), ERF required for nodulation $(G m E R N)$, nodulation signaling pathway $2 b$ (GmNSP2b), and nodulation inception genes (GmNIN1a, GmNIN2a, and $G m N I N 2 b$ ), were upregulated. Moreover, the expressions of glutamate synthase (GmGOGAT), asparagine synthase (GmAS), nitrite reductase $(G m N i R)$, ammonia transporter (GmSATI), leghemoglobin $(G m L b)$, and nifH involved in nitrogen metabolism were upregulated in NaHS-treated soybean roots and nodules. Together, our results suggested that $\mathrm{H}_{2} \mathrm{~S}$ may act as a positive signaling molecule in the soybean-rhizobia symbiotic system and enhance the system's nitrogen fixation ability.
\end{abstract}

Keywords: gene expression, hydrogen sulfide, molecular signaling, nitrogen fixation, nitrogenase activity, nodulation, rhizobiumlegume symbiosis, symbiosis

${ }^{\dagger}$ Corresponding authors: J. Chen; chenjuan@nwsuaf.edu.cn; and G.-H. Wei; weigehong@ @ nwsuaf.edu.cn

Funding: This study was financially supported by the National Natural Science Foundation of China (31501822, 41830755, and 41671261) and the China Postdoctoral Science Foundation (2015M580876 and 2016T90948).

*The $\boldsymbol{e}$-Xtra logo stands for "electronic extra" and indicates that five supplementary figures and two supplementary tables are published online.

The author(s) declare no conflict of interest.

๑) 2019 The American Phytopathological Society
Symbiosis is ubiquitous in terrestrial, freshwater, and marine communities. It has played a key role in the emergence of major life forms on Earth, and in the generation of biological diversity (Moran 2006). Among all plant-microorganism symbioses, mutualism between legumes and bacteria known as rhizobia is the most well studied (Caballero-Mellado and MartinezRomero 1999). Symbiotic infection by rhizobia into legume roots leads to the formation of a specialized organ known as the root nodule, in which rhizobia differentiate into nitrogen-fixing bacteroids (Mergaert et al. 2006). Root nodules not only create an optimized environment for nitrogen fixation but also provide a site where substance exchange can take place in plants (Becana and Sprent 1987). In exchange for atmospheric nitrogen fixed by bacteroids, legumes provide energy and carbon sources to the bacterial partner (Werner et al. 2015).

In recent years, overuse of nitrogen fertilizers aimed at increasing soybean (Glycine max) and other crop yields has led to widespread environmental problems (Tian et al. 2012). Counterproductively, nitrogen fertilizer overuse does not promote soybean production because the redundancy of inorganic nitrogen in the soil layer surrounding roots inhibits nodulation and biological nitrogen fixation (Tilman et al. 2002). This reduced the utilization efficiency of nitrogen fertilizers and caused acidification and hardening of soil, along with various environmental problems. Thus, enhancing the nitrogen-fixing ability of the soybean-rhizobia symbiotic system is a practical solution for reducing the overuse of nitrogen fertilizers and preventing subsequent environmental problems (MasclauxDaubresse et al. 2010).

The establishment of symbiosis between plants and microorganisms involves a complex regulatory network that includes nitric oxide (NO) and reactive oxygen species (ROS) (Fukuto et al. 2012; Li et al. 2011; Oldroyd 2013). NO is produced in functional root nodules and is crucial for the establishment of symbiosis between Medicago truncatula and Sinorhizobium meliloti (Baudouin et al. 2006; del Giudice et al. 2011). The production of NO during the infection process indicates a role for this gaseous molecule in recognition between plants and their bacterial partners (Hichri et al. 2016). Similar findings reported by Pii et al. (2007) suggested that NO and auxins may control the formation of indeterminate nodules in M. truncatula. Meanwhile, NO is also crucial for the development of functional nodules in soybean, as demonstrated by Leach et al. (2010) using a NO synthase-specific inhibitor. Furthermore, ROS and NO may synergistically control the early stages of the formation of 
legume-rhizobia symbiosis (Damiani et al. 2016). Additionally, NO have a negative effect on nitrogenase (Nase) activity in plants (Cam et al. 2012; Meilhoc et al. 2010).

Recently, the role of hydrogen sulfide $\left(\mathrm{H}_{2} \mathrm{~S}\right)$ as a signaling molecule in regulating physiological processes in plants has become a hot topic. In addition to participating in adventitious root and lateral root formation and seed germination (Lin et al. 2012; Zhang et al. 2009; Zhang et al. 2008), $\mathrm{H}_{2} \mathrm{~S}$ is reportedly involved in alleviating oxidative damage caused by heavy metals such as aluminum, copper, boron, cadmium, and chromium (Chen et al. 2013; Fang et al. 2016; Li et al. 2012b; Sun et al. 2013; B. L. Wang et al. 2010; Zhang et al. 2010). Moreover, $\mathrm{H}_{2} \mathrm{~S}$ also acts as an antioxidant signaling molecule to modulate ROS and antioxidant levels, thereby improving drought tolerance in soybean (Zhang et al. 2010). Alternatively, $\mathrm{H}_{2} \mathrm{~S}$ enhances the drought tolerance of plants by affecting the biosynthesis and expression levels of genes associated with polyamines and soluble sugars (Chen et al. 2016). $\mathrm{H}_{2} \mathrm{~S}$ also appears to alleviate saline-induced stress responses in bermudagrass (Cynodon dactylon) (Shi et al. 2013). Shen et al. (2013) found that $\mathrm{H}_{2} \mathrm{~S}$ conferred drought tolerance in Arabidopsis thaliana through affecting microRNA expression. Moreover, $\mathrm{H}_{2} \mathrm{~S}$ regulates stomatal movements together with NO, abscisic acid, and inward-rectifying $\mathrm{K}^{+}$channels (García-Mata and Lamattina 2010; Papanatsiou et al. 2015; Scuffi et al. 2014). Chen et al. (2011) reported that $\mathrm{H}_{2} \mathrm{~S}$ promotes photosynthesis by increasing ribulose-1,5-bisphosphate carboxylase activity, and through thiol redox modification in Spinacia oleracea. Other studies indicate a role for $\mathrm{H}_{2} \mathrm{~S}$ in autophagy (Álvarez et al. 2012; Laureano-Marín et al. 2016; Romero et al. 2014). In both animals and plants, most $\mathrm{H}_{2} \mathrm{~S}$ responses are related to or mediated by NO or ROS (Laureano-Marín et al. 2016; Li et al. 2013; Scuffi et al. 2014; Zhang et al. 2009). However, whether $\mathrm{H}_{2} \mathrm{~S}$ exerts synergistic or similar functions in the formation of legume-rhizobia symbiosis remains unclear.

In the present study, we found that treatment with an $\mathrm{H}_{2} \mathrm{~S}$ donor (sodium hydrosulfide [NaHS]) promotes infection of Sinorhizobium fredii into soybean roots, and enhances the biological nitrogen-fixation ability of the symbiotic system by upregulating symbiosis and nitrogen-fixation-related genes and proteins. Stimulation of nitrogen fixation and metabolism led to enhanced nitrogen assimilation and photosynthesis in soybean plants, which eventually promoted plant growth. This is the first study to investigate the regulatory role of $\mathrm{H}_{2} \mathrm{~S}$ in the legumerhizobia symbiotic system, and our findings suggest that $\mathrm{H}_{2} \mathrm{~S}$ is a positive regulator in the establishment of symbiosis and symbiotic nitrogen fixation between $G$. $\max$ and $S$. fredii. This research will likely inspire future study of the role of $\mathrm{H}_{2} \mathrm{~S}$ in plant physiology, and might offer a possible solution to increasing soybean production.

\section{RESULTS}

\section{Exogenous addition of $\mathrm{H}_{2} \mathrm{~S}$ donor promotes soybean plant growth.}

To find the optimal concentration of NaHS for the growth of soybean, different concentrations $(0,10,25,50,100,250$, and $500 \mu \mathrm{M}$ ) were used to treat soybean plants and $S$. fredii in liquid culture medium in our preliminary experiments. For $S$. fredii, $100 \mu \mathrm{M}$ NaHS was shown to be the maximal concentration that did not significantly impact rhizobial growth (Supplementary Fig. S1). For soybean plants, $100 \mu \mathrm{M}$ NaHS was the optimal concentration for root length, shoot length, and biomass yield (Supplementary Fig. S2). These preliminary results were in agreement with those of previous studies by Chen et al. (2011), Christou et al. (2014), and Tamizhselvi et al. (2007) using other plant materials. Then, to explore the regulatory effects of $\mathrm{H}_{2} \mathrm{~S}$ on soybean plant growth and symbiosis with $S$. fredii, $10 \mathrm{ml}$ of
$100 \mu \mathrm{M}$ NaHS solution was used to treat each soybean roots, and the growth of roots and shoots was measured after inoculation. In both inoculated and noninoculated groups, NaHS treatment promoted root elongation (Fig. 1A). In the inoculated plants, average root length was promoted by NaHS treatment at most of the checkpoints, and this increase in root length was turned out to be statistically significant $(F=7.318, P=0.042)$ by repeated measure $(\mathrm{RM})$ analysis of variance (ANOVA) of the general linear model (GLM). In the noninoculated plants, NaHS treatment also slightly extended the average root length but the extension of root length by NaHS treatment was not significant (RM GLM, $F=1.393, P=0.197$ ). Similar results were observed in soybean shoots. NaHS treatment did not have a significant effect on shoot elongation in noninoculated soybean plants (RM GLM, $F=1.618, P=0.227$ ) (Fig. 1B). However, in the inoculated soybean plants, the average shoot length was significantly increased by NaHS treatment (RM GLM, $F=8.774, P=$ 0.037) (Fig. 1B). The biomass of dry matter in inoculated soybean roots treated with NaHS was significantly higher compared with control plants (RM GLM, $F=6.475, P=0.043$ ). However, there was no significant difference observed among the noninoculated groups (RM GLM, $F=3.017, P=0.061$ ) (Fig. 1C). $\mathrm{NaHS}$ also significantly increased the biomass of dry matter in soybean shoots (RM GLM, $F=6.911, P=0.041$ ). No difference in shoot dry weight was observed in the noninoculated plants (Fig. 1D). Taken together, these results demonstrated that NaHS treatment promoted the growth of soybean seedlings, especially the growth of soybean roots under symbiotic conditions.

\section{Exogenous addition of the $\mathrm{H}_{2} \mathrm{~S}$ donor promotes} rhizobial infection, root nodulation, and Nase activity.

We counted the number of nodules on each harvested soybean root at 7, 14, 21, 28, 35, and 42 days postinoculation (DPI) to determine the effects of NaHS on nodulation in soybean plant. The result showed that $\mathrm{H}_{2} \mathrm{~S}$ promoted soybean nodulation (RM GLM, $F=7.733, P=0.037$ ) (Fig. 2A). Meanwhile, the addition of NaHS promoted not only soybean nodulation but also the nitrogen fixation ability of these nodules. The Nase activity assay, which was measured by the acetylene reduction (AR) analysis, showed that NaHS treatment significantly increased Nase activity in root nodules (RM GLM, $F=17.094$, $P=0.015$ ) (Fig. 2B). The AR ability showed significant increase compared with the control; these results suggested that $\mathrm{H}_{2} \mathrm{~S}$ promoted soybean nodulation and enhanced the nitrogenfixing potential of the soybean-rhizobia symbiotic system.

Additionally, another phenotypic analysis of infection events was conducted to further delineate the effect of NaHS treatment on soybean nodulation. Root hair curling, infection threads, and nodule primordia formed during the nodulation process were observed and counted (Fig. 2C). At 5 DPI, more root hair curling and developing infection threads were found in NaHStreated soybean roots (Fig. 2C). However, no significant difference in number of developing infection threads and nodule primordia were found between NaHS-treated and untreated soybean roots. At 7 DPI, cortex infection threads in NaHStreated soybean roots were more abundant than those in untreated controls (Fig. 2D). These results suggested that $\mathrm{H}_{2} \mathrm{~S}$ may act as a positive regulator of soybean nodulation.

\section{Exogenous addition of an $\mathrm{H}_{2} \mathrm{~S}$ donor increases endogenous $\mathrm{H}_{2} \mathrm{~S}$ concentration in soybean roots and nodules.}

To confirm that the observed changes were caused by the $\mathrm{H}_{2} \mathrm{~S}$ released from $\mathrm{NaHS}$, we used an $\mathrm{H}_{2} \mathrm{~S}$-specific fluorescence probe to measure the amount of endogenous $\mathrm{H}_{2} \mathrm{~S}$ in soybean plant tissues, including lateral root, main root, and nodule. Endogenous $\mathrm{H}_{2} \mathrm{~S}$ was measured in different soybean tissues after loading with the sulfidefluor-7-acetoxymethyl ester 
(SF7-AM) probe (Fig. 3; Supplementary Fig. S3). Before NaHS treatment, the observed low fluorescence intensity indicated a low concentration of endogenous $\mathrm{H}_{2} \mathrm{~S}$ in these tissues (Fig. 3G, H, and I). After treatment with $100 \mu \mathrm{M}$ NaHS, higher fluorescence intensity was observed, indicating that NaHS increases the endogenous $\mathrm{H}_{2} \mathrm{~S}$ concentration in these tissues (Fig. 3J, K, and L).
Due to the drastic increase of fluorescence intensity by the NaHS treatment, we may rule out the possibility that this strong fluorescence was caused by autofluorescence. The effect of NaHS treatment on endogenous $\mathrm{H}_{2} \mathrm{~S}$ concentration in plant tissues was also verified by quantification of the fluorescence intensity in these tissues.
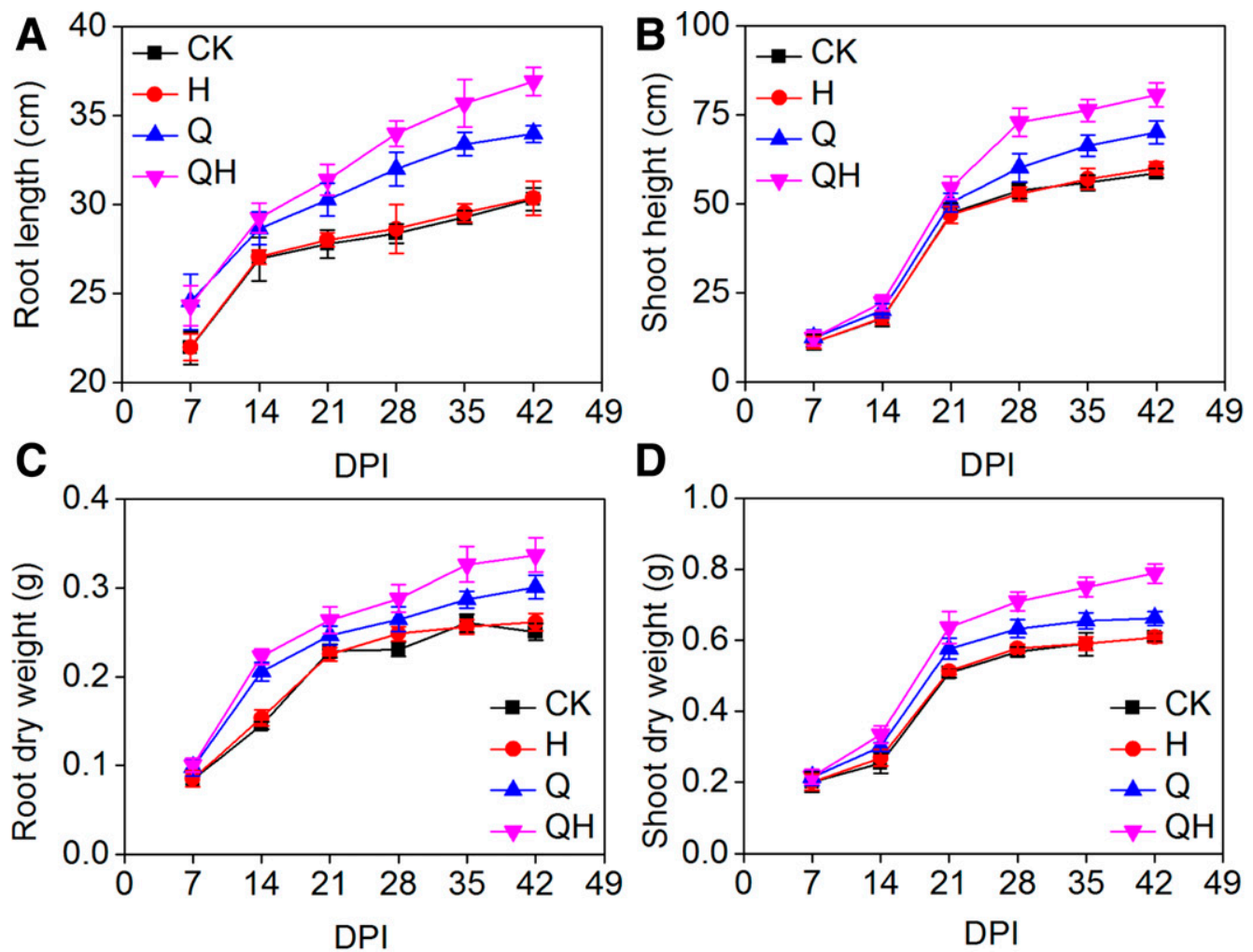

$\mathbf{E}$

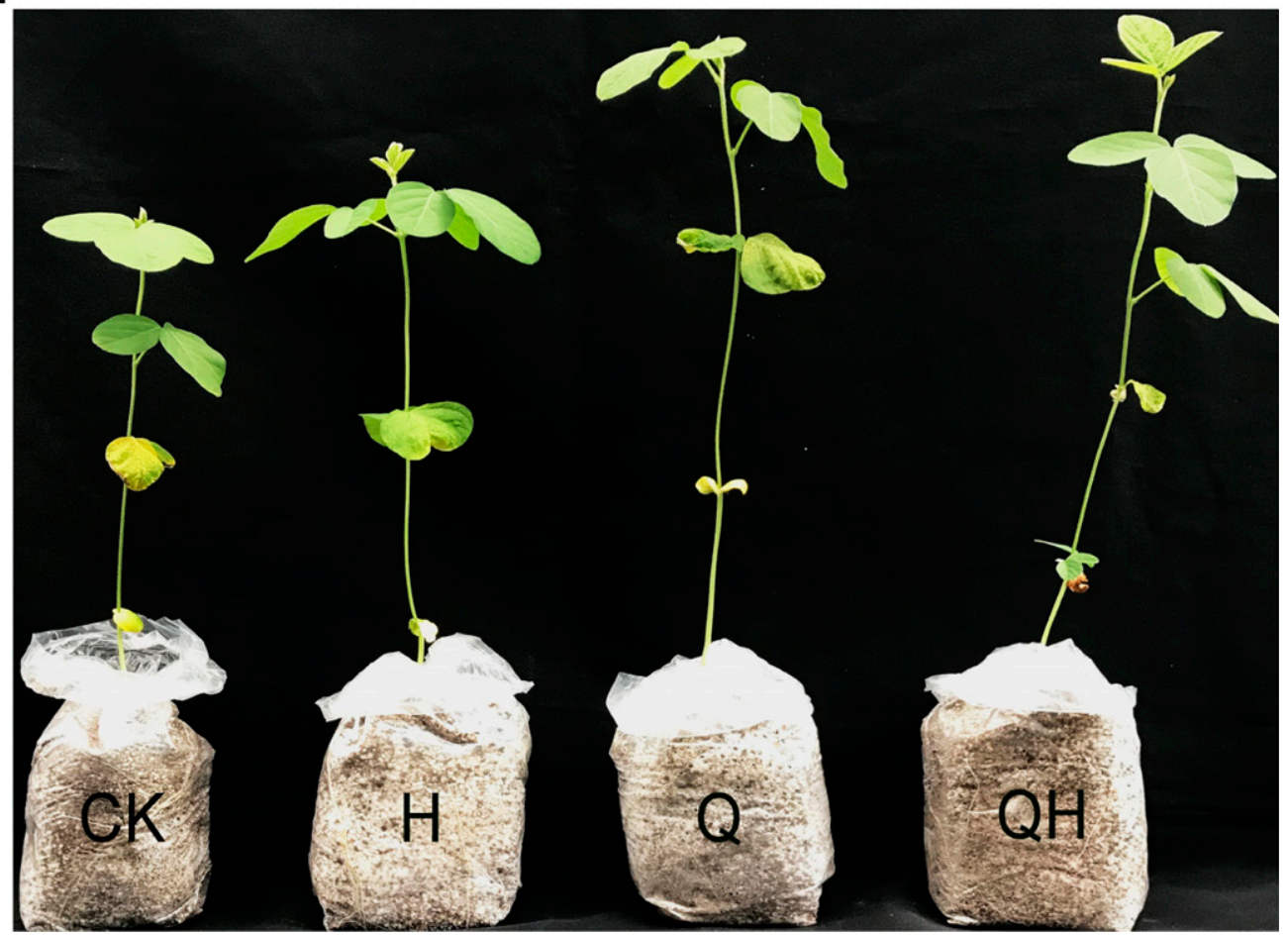

Fig. 1. Hydrogen sulfide's effect on the growth of soybean seedlings. Time course of $\mathbf{A}$ and $\mathbf{B}$, root and shoot length and $\mathbf{C}$ and $\mathbf{D}$, dry weight for soybean plants. E, Soybean plants following different treatments at 14 days postinoculation (DPI). Soybean plants were harvested every 7 days since inoculation. CK $=$ controls, $\mathrm{H}=100 \mu \mathrm{M}$ sodium hydrosulfide (NaHS), Q = soybean seedlings inoculated with Sinorhizobium fredii Q8 strain, and QH = soybean seedlings inoculated with S. fredii Q8 strain and treated with $100 \mu \mathrm{M}$ NaHS. Three independent experiments were conducted. Values are means \pm standard error $(n=60)$. 
To further evaluate the effect of NaHS treatment, we measured the $\mathrm{H}_{2} \mathrm{~S}$ content in plant tissues using methylene blue method, as described by Zhang et al. (2008). As the results of the methylene blue assay suggested, the $\mathrm{H}_{2} \mathrm{~S}$ contents in lateral roots, main roots, and root nodules were significantly increased by NaHS treatment (Fig. 4). Together, these results indicated that NaHS treatment could significantly increase the $\mathrm{H}_{2} \mathrm{~S}$ concentration in soybean tissues.

\section{$\mathrm{H}_{2} \mathrm{~S}$ did not influence nodule structure.}

We used a light microscope to determine whether $\mathrm{H}_{2} \mathrm{~S}$ could lead to structural change in nodules. According to the observation, the paraffin sections of nodules obtained at different times did not exhibit any significant difference between NaHStreated nodules and control nodules (Supplementary Fig. S4).

Similarly, transmission electron microscopy (TEM) was then conducted to observe the microscopic structure of infected cells and bacteroids in nodules. Bacteroids in nodules harvested at 14, 21, and 28 DPI exhibited typical morphological characteristics, and no obvious differences were found between NaHStreated nodules and controls. Taken together, $\mathrm{H}_{2} \mathrm{~S}$ did not exhibit any significant effect on rhizobia colonization and bacteroid differentiation in root nodules.

Chlorophyll content, photosynthesis intensity, and photosystem II activity are elevated by $\mathrm{H}_{2} \mathrm{~S}$.

NaHS treatment increased the chlorophyll content in both inoculated and noninoculated plants from 7 to 42 DPI. In the inoculated soybean plants, the chlorophyll content in soybean leaves was significantly increased by NaHS treatment (RM GLM, $F=15.991, P=0.020$ ) whereas, in the noninoculated plants, NaHS did not make any significant difference (RM GLM, $F=3.512, P=0.094$ ) (Fig. 5A). A net photosynthetic rate $(\mathrm{Pn})$ curve showed that NaHS treatment enhanced the photosynthesis in soybean leaves in the inoculated plants (RM GLM, $F=19.243, P=0.013)$. Again, NaHS treatment did not influence Pn in noninoculated plants (RM GLM, $F=3.249, P=$ 0.081) (Fig. 5B).

In terms of chlorophyll fluorescence parameters, the quantum yield of photosystem II photochemistry (PSII), the ratio of variable fluorescence $(\mathrm{Fv})$ to maximum fluorescence $(\mathrm{Fm})(\mathrm{Fv} / \mathrm{Fm})$, and photochemical efficiency of PSII in the light $\left(\mathrm{Fv}^{\prime} / \mathrm{Fm}^{\prime}\right)$ followed a similar trend after treatment with $100 \mu \mathrm{M}$ NaHS (Fig. $6)$. In the noninoculated group, there was not a significant difference in PSII between NaHS-treated soybean plants and control plants (RM GLM, $F=3.119, P=0.068$ ). However, in the inoculated group, PSII in NaHS-treated plants was higher than in controls (RM GLM, $F=8.739, P=0.031$ ) (Fig. 6A). Fv/Fm in inoculated plants was higher than in noninoculated plants. NaHS treatment significantly increased $\mathrm{Fv} / \mathrm{Fm}$ in the inoculated soybean leaves (RM GLM, $F=9.287, P=0.034$ ). However, in the noninoculated group, there was no significant difference between NaHS-treated and control plants during the entire testing period (RM GLM, $F=2.668, P=0.148$ ) (Fig. 6B). In noninoculated plants, NaHS treatment did not affect $\mathrm{Fv}^{\prime} / \mathrm{Fm}^{\prime}$ (RM GLM, $F=$ $1.577, P=0.203$ ). However, in inoculated plants, $\mathrm{Fv}^{\prime} / \mathrm{Fm}^{\prime}$ in
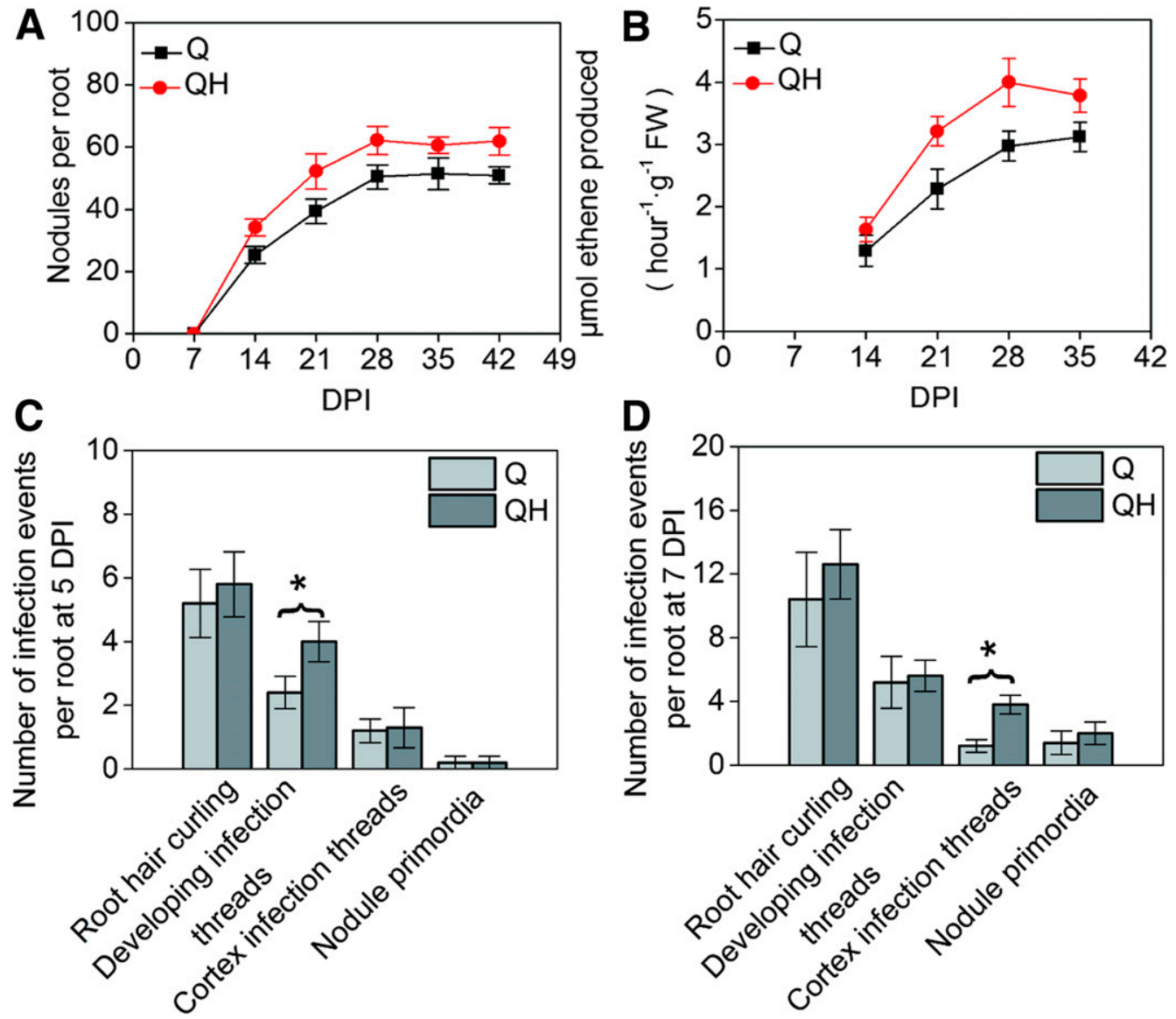

Fig. 2. Hydrogen sulfide's effect on soybean nodulation and nitrogenase (Nase) activities. A, Root nodule number and B, nitrogenase activity assay. Infection events assay at $\mathbf{C}, 5$ and $\mathbf{D}, 7$ days postinoculation (DPI). An asterisk $(*)$ indicates significant difference $(P<0.05)$. Q $=$ soybean seedlings inoculated with Sinorhizobium fredii Q8 strain and $\mathrm{QH}=$ soybean seedlings inoculated with $S$. fredii Q8 strain and treated with $100 \mu \mathrm{M}$ sodium hydrosulfide. Three independent experiments were conducted. For nodule number, values are means \pm standard error $(\mathrm{SE})(n=60)$. For Nase activity, values are means \pm SE $(n=45)$. 
NaHS-treated plants was higher than in controls (RM GLM, $F=$ 8.442, $P=0.038$ ) (Fig. 6C).

\section{$\mathrm{H}_{2} \mathrm{~S}$ affects symbiosis and} nitrogen fixation-related protein expression.

Western blotting analysis of chalcone synthase (CHS) and the Nase iron-containing protein (nifH) were conducted to investigate the regulatory effects of $\mathrm{H}_{2} \mathrm{~S}$ on the expression of key proteins involved in symbiotic establishment and nitrogen fixation. The result of Western blotting indicated that NaHS treatment significantly increased the protein expression level of nifH in root nodules. At 14, 21, 28, and 35 DPI, the abundances of nifH protein were significantly higher than that in the control nodules (Fig. 7A and $\mathrm{B}$ ). However, $\mathrm{H}_{2} \mathrm{~S}$ did not trigger any significant changes in the protein expression abundance of CHS in NaHS-treated soybean root nodules compared with the nontreated controls (Fig. 7A and C).

\section{Quantitative real-time polymerase chain reaction analysis} of the expression of symbiosis-related gene.

To further elucidate the mechanism with which $\mathrm{H}_{2} \mathrm{~S}$ promoted nodulation in soybean, we examined the expression profile of several nodulation marker genes in soybean roots, including GmENOD40, GmERN, GmNSP2b, GmNINIa, $G m N I N 2 a$, and GmNIN2b. We selected $12 \mathrm{~h}$ postinoculation and $1,3,5$, and 7 DPI of $S$. fredii as checkpoints. The quantitative real-time polymerase chain reaction (qRT-PCR) results demonstrated that $\mathrm{H}_{2} \mathrm{~S}$ stimulated the expression levels of these genes in soybean roots. For instance, RM ANOVA of the GLM suggested that NaHS treatment affected the expression level of these genes (Fig. 8). In the inoculated roots, the expression level of GmENOD4O gene was higher in NaHS-treated roots (RM GLM, $F=10.253, P=0.021)$. NaHS did not make any significant difference in expression of GmENOD40 of the noninoculated soybean roots (RM GLM, $F=2.032, P=0.169$ ) (Fig. 8A). Similarly, expression of GmERN (RM GLM, $F=$ 9.369, $P=0.034$ ) and $G m N S P 2 b$ (RM GLM, $F=7.318$,

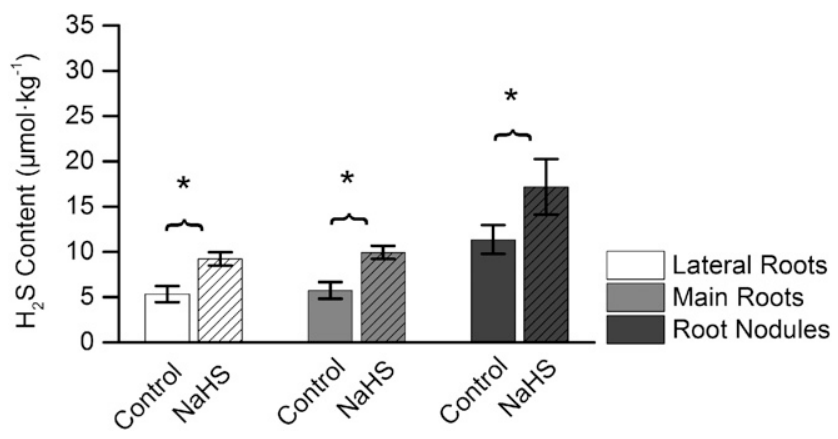

Fig. 4. Quantification of hydrogen sulfide $\left(\mathrm{H}_{2} \mathrm{~S}\right)$ in soybean tissues with methylene blue method. NaHS $=$ sodium hydrosulfide. An asterisk $(*)$ indicates significant difference $(P<0.05)$. Three independent experiments were conducted. Values are means \pm standard error $(n=30)$.

Bright Field

Lateral Root

A
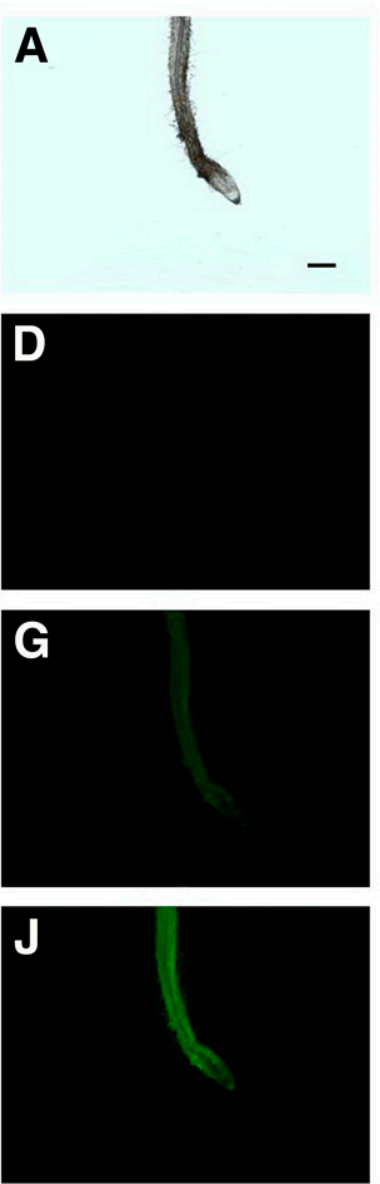

Main Root
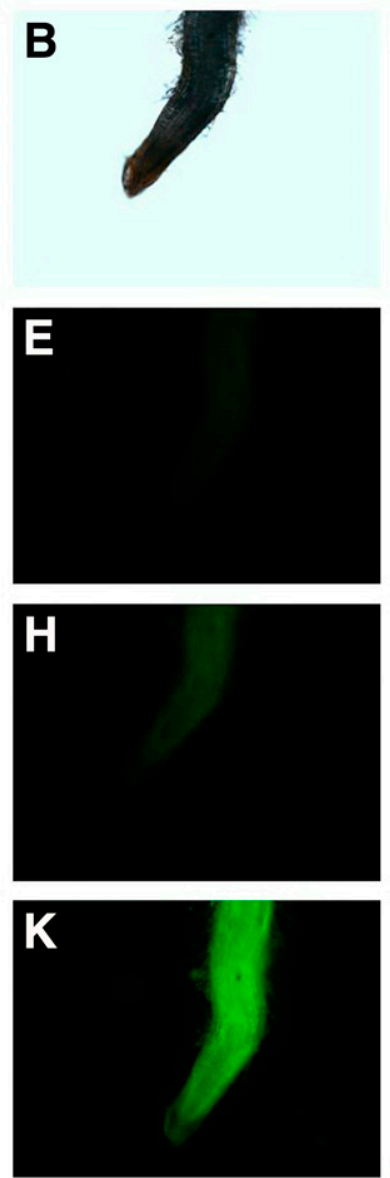

Root Nodule
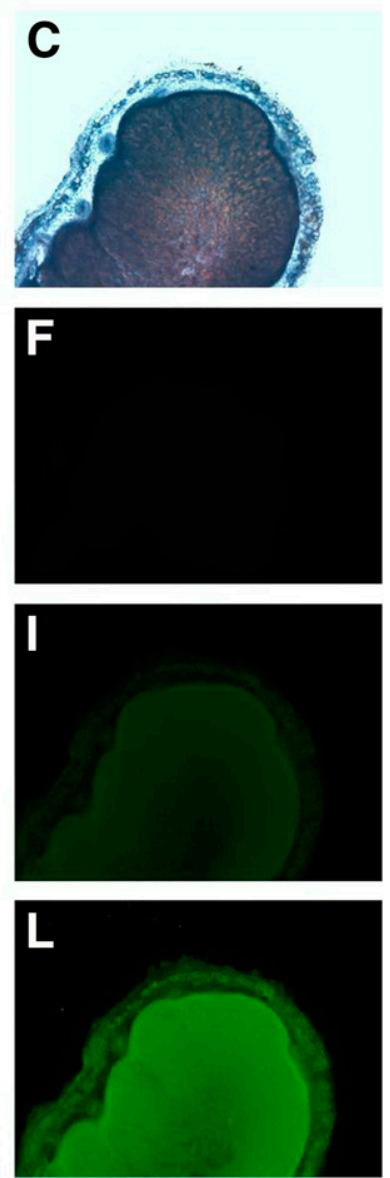

Fig. 3. Fluorescence probe assay of endogenous hydrogen sulfide $\left(\mathrm{H}_{2} \mathrm{~S}\right)$ in different soybean plant tissues. A to $\mathbf{C}$, Bright field images of untreated plant tissues. D to $\mathbf{F}$, Fluorescent field images of untreated plant tissues. G to I, Fluorescent field images of tissues loaded with $\mathrm{H}_{2} \mathrm{~S}$-specific fluorescence sulfidefluor-7acetoxymethyl ester (SF7-AM) probe. $\mathbf{J}$ to $\mathbf{L}$, Fluorescent field images of tissues loaded with SF7-AM and treated with $100 \mu \mathrm{M}$ sodium hydrosulfide (NaHS). $\mathrm{Bar}=200 \mu \mathrm{m}$ and $\lambda \mathrm{ex}=488 \mathrm{~nm}$. 
$P=0.038$ ) were also induced by NaHS treatment in inoculated roots. In the noninoculated soybean roots, the expression of both $G m E R N$ (RM GLM, $F=2.798, P=0.137$ ) and $G m N S P 2 b$ ( $F=2.301, P=0.148)$ were not affected by NaHS treatment (Fig. 8B and C). Expression level of GmNIN1a was also stimulated by $\mathrm{H}_{2} \mathrm{~S}$ in the inoculated soybean roots (RM GLM, $F=14.837, P=0.015)$. In noninoculated roots, GmNINI $a$ was not influenced by $\mathrm{H}_{2} \mathrm{~S}$. On the other hand, GmNIN2a $(F=$ $11.311, P=0.020)$ and $G m N I N 2 b(F=7.079, P=0.041)$ expression in inoculated roots were stimulated by NaHS treatment only from 3 to 7 DPI (Fig. 8E and F). Again, NaHS treatment did not provoke any significant difference in the noninoculated soybean roots.

We also used exogenous flavonoids to treat $S$. fredii. In this circumstance, the expression of $\operatorname{nod} A, \operatorname{nod} C$, and $\operatorname{nod} D$ genes of $S$. fredii was examined to verify whether NaHS treatment could also induce the symbiotic reaction in rhizobia. In this quantitative assay, both NaHS-treated and nontreated $S$. fredii cells in tryptone-yeast (TY) liquid medium were collected at $0,0.5,2$, 5,12 , and $24 \mathrm{~h}$ after the addition of the mixture of genistein and glycitein. The qRT-PCR result suggested that exogenous flavonoids successfully simulated the symbiotic signaling by soybean roots which induced the expression of rhizobial nodA, $\operatorname{nod} C$, and nodD genes, and the expression levels of nodA, nod $C$, and nodD genes were upregulated by NaHS treatment (RM GLM, $F=9.183, P=0.021 ; F=12.619, P=0.018$; and $F=21.773, P=0.008$, respectively) (Fig. 8).

qRT-PCR analysis of the relative expression of key enzymes related to nitrogen metabolism.

Expression of nitrogen-metabolism-related genes was investigated to determine the possible influence of $\mathrm{H}_{2} \mathrm{~S}$ on the molecular mechanisms of symbiotic nitrogen fixation and nitrogen metabolism in soybean plants. Glutamate synthase $(G m G O G A T)$, asparagine synthase $(G m A S)$, nitrite reductase (GmNiR), ammonia transporter SAT1 (GmSAT1), leghemoglobin $(G m L b)$ in soybean plant, and nifH in $S$. fredii were selected for qRT-PCR analysis.

The transcript abundances of GmGOGAT was increased in the inoculated roots by NaHS treatment from 14 to 35 DPI (RM GLM, $F=9.335, P=0.034$ ) (Fig. 9A). Similarly, the expression of $G m A S$ and GmSATl was also enhanced in the NaHS-treated roots from 14 to $35 \mathrm{DPI}$ (RM GLM, $F=8.821, P=0.036$; and $F=8.013, P=0.039$, respectively) (Fig. 9B and D). However, $\mathrm{NaHS}$ treatment significantly upregulated the expression of $G m N i R$ in the whole experimental period from 5 to 35 DPI (RM GLM, $F=13.337, P=0.026$ ) (Fig. 9C). Moreover, NaHS treatment also significantly upregulated the expression of nitrogen-fixation-related $G m L b$ and rhizobial nifH genes (RM GLM, $F=8.973, P=0.032$; and $F=6.991, P=0.047$, respectively) (Fig. 9E and F).

\section{DISCUSSION}

\section{$\mathrm{H}_{2} \mathrm{~S}$ promotes soybean plant growth} in the soybean-rhizobia symbiotic system.

$\mathrm{NaHS}$ has been used as an exogenous $\mathrm{H}_{2} \mathrm{~S}$ donor to study the physiological effects of $\mathrm{H}_{2} \mathrm{~S}$ in many studies (Z. G. Li et al. 2012; Shi et al. 2013; Tamizhselvi et al. 2007; M. J. Wang et al. 2010). Numerous experiments have shown that $\mathrm{H}_{2} \mathrm{~S}$ can cause various biological effects in plants. In addition to alleviation of abiotic stresses such as heavy metals, heat, drought, and mineral salts (Chen et al. 2016; L. Li et al. 2012; Z. G. Li et al. 2012; Shi et al. 2013; Zhang et al. 2008), $\mathrm{H}_{2} \mathrm{~S}$ was also found to be
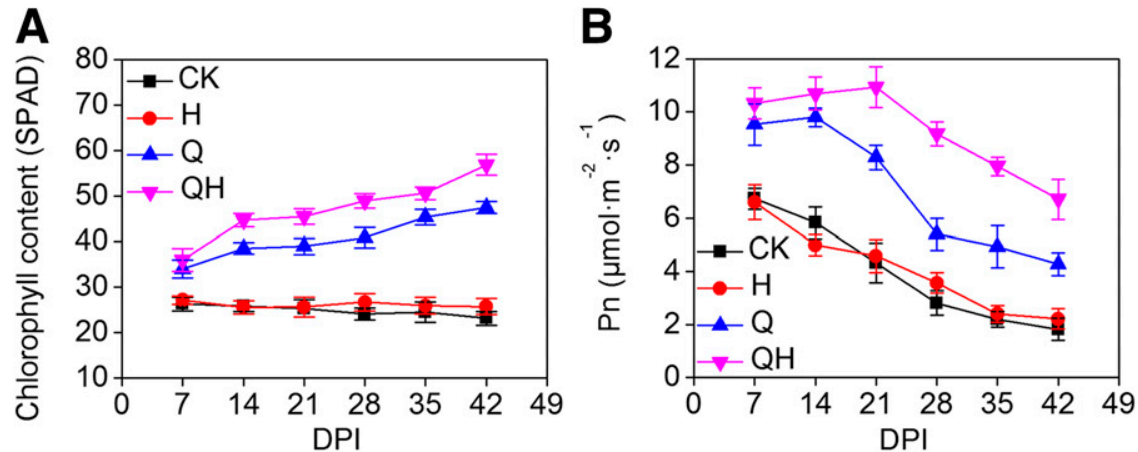

Fig. 5. Hydrogen sulfide's effect on photosynthetic parameters. A, Chlorophyll content and $\mathbf{B}$, net photosynthetic rate $(\mathrm{Pn})$. $\mathrm{CK}=\mathrm{controls}, \mathrm{H}=100 \mu \mathrm{M}$ sodium hydrosulfide (NaHS), Q = soybean seedlings inoculated with Sinorhizobium fredii Q8 strain, and QH = soybean seedlings inoculated with S. fredii Q8 strain and treated with $100 \mu \mathrm{M}$ NaHS. DPI = days postinoculation. Three independent experiments were conducted. Values are means \pm standard error $(n=60)$.
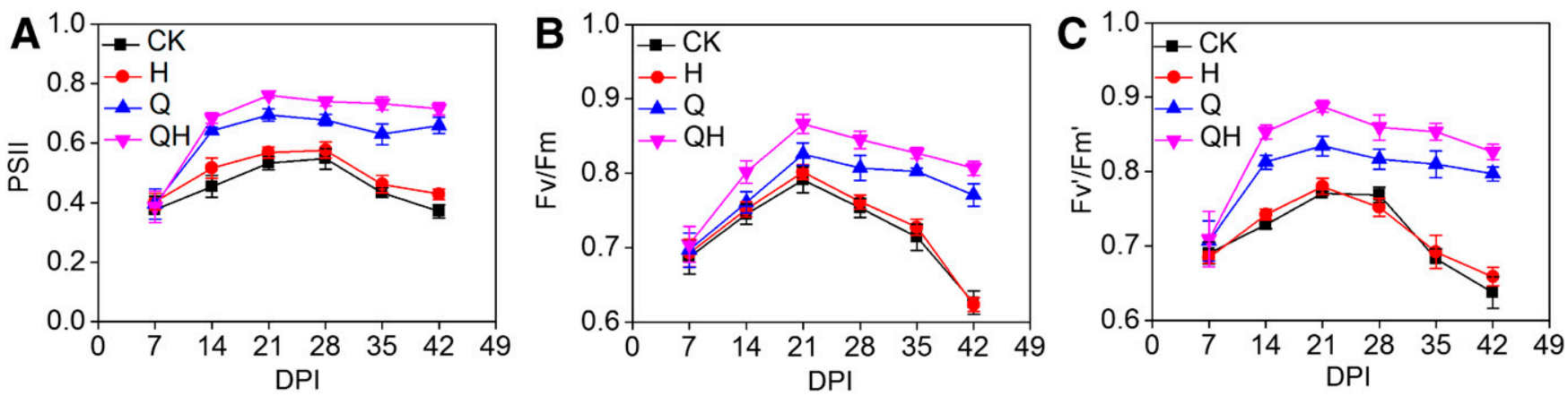

Fig. 6. Hydrogen sulfide's effect on chlorophyll fluorescent parameters. A, Quantum yield of photosystem II photochemistry (PSII). B, Ratio of variable fluorescence to maximum fluorescence (Fv/Fm). C, Photochemical efficiency of PSII in the light $\left(\mathrm{Fv}^{\prime} / \mathrm{Fm}^{\prime}\right)$. CK $=$ controls, $\mathrm{H}=100 \mu \mathrm{M}$ sodium hydrosulfide (NaHS), Q = soybean seedlings inoculated with Sinorhizobium fredii Q8 strain, and QH = soybean seedlings inoculated with S. fredii Q8 strain and treated with $100 \mu \mathrm{M}$ NaHS. DPI = days postinoculation. Three independent experiments were conducted. Values are means \pm standard error $(n=60)$. 
involved in regulating plant growth via different mechanisms (Chen et al. 2011; Dooley et al. 2013; Zhang et al. 2011). In the present study, we found that exogenous $\mathrm{H}_{2} \mathrm{~S}$ promoted the growth of soybean plants under symbiotic conditions with $S$. fredii (Fig. 1). In the inoculated soybean plants, NaHS treatment increased the root length and dry weight (Fig. 1A and C). This indicated that $\mathrm{H}_{2} \mathrm{~S}$ promoted the formation and development of roots, which is consistent with the findings of Zhang et al. (2009) in sweet potato. Moreover, the shoot length and dry weight were also promoted by NaHS treatment (Fig. 1B and D). Although sulfur (S) is an essential nutrient element for plants, complex regulatory networks have evolved to tightly balance $S$, uptake, transport and metabolization during changes of supply and demand. Although, in the present study, the nitrogen-free nutrient solution supplied sufficient $\mathrm{S}$ for plant growth $(64.33 \mathrm{mg} / \mathrm{liter})$ according to the description by Chandra and Pandey (2016), soybean plants were unlikely to suffer from $\mathrm{S}$ starvation during the treatment. In addition, the $\mathrm{S}$ content in the NaHS treatment was much lower than that in the nitrogen-free nutrient solution (approximately 1:25); thus, we may rule out the possibility that the dry weight accumulation and growth increase were due to the NaHS-treated soybean receiving more $\mathrm{S}$ as nutrient. Together, these results indicated a potential role for $\mathrm{H}_{2} \mathrm{~S}$ in regulating the symbiosis between $G$. $\max$ and $S$. fredii, which could promote symbiotic nitrogen fixation and, consequently, plant growth of soybean.

\section{$\mathrm{H}_{2} \mathrm{~S}$ promotes the formation}

of root nodules and Nase activity.

Nitrogen-fixing nodules formed by the symbiosis of rhizobia and legume plants are essential for fixation of nitrogen in the environment (Lee et al. 2014). The nodulation process is regulated by two critical systemic signaling events. The first is the recognition of the two symbiotic partners and the initiation of nodulation, which occurs in the rhizosphere. The second occurs within the plant to regulate the number of nodules as a means of balancing the resource cost and nitrogen benefit associated with nodulation (Hayashi et al. 2013). Many small molecules such as $\mathrm{NO}, \mathrm{H}_{2} \mathrm{O}_{2}$, and phytohormones have been reported to be involved in the regulation of nodulation between legumes and rhizobia (Hérouart et al. 2002; Hirsch et al. 1997; Puppo et al. 2013). Here, we demonstrated that exogenous $\mathrm{H}_{2} \mathrm{~S}$ could promote soybean nodulation (Fig. 2A). On the other hand, Nase is the essential enzyme for symbiotic nitrogen fixation that catalyzes the conversion of dinitrogen into ammonia (Fishbeck et al. 1973). Our results suggested that Nase activity in NaHStreated nodules was enhanced in the NaHS-treated nodules (Fig. 2B). This enhanced Nase activity may promote the nitrogen fixation potential of the NaHS-treated soybean plants.

In the $M$. truncatula-S. meliloti system, del Giudice et al. (2011) confirmed the crucial position of NO in successful infection. Studies in Arabidopsis have shown that auxin accumulation is a prerequisite for organ formation in plants (Ferguson and Mathesius 2014). External treatment of roots with auxins and auxin action inhibitors suppressed nodule formation, indicating that auxins are required for nodulation within a certain concentration range in $M$. truncatula (van Noorden et al. 2006). Infection event assays showed that, during the early stages of the establishment of symbiosis, a larger number of infection events occurred in NaHS-treated soybean roots (Fig. 2C and D). Our results here suggested that $\mathrm{H}_{2} \mathrm{~S}$ may

A

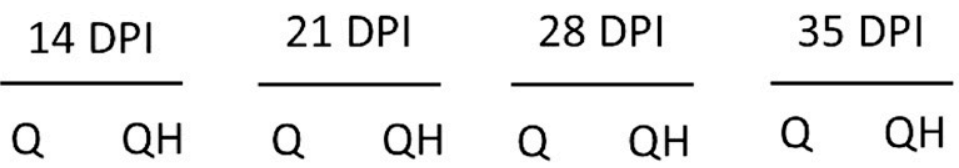

$\mathrm{NifH}(32.5 \mathrm{KD})$

CHS (43.1 KD)

Actin (45 KD)

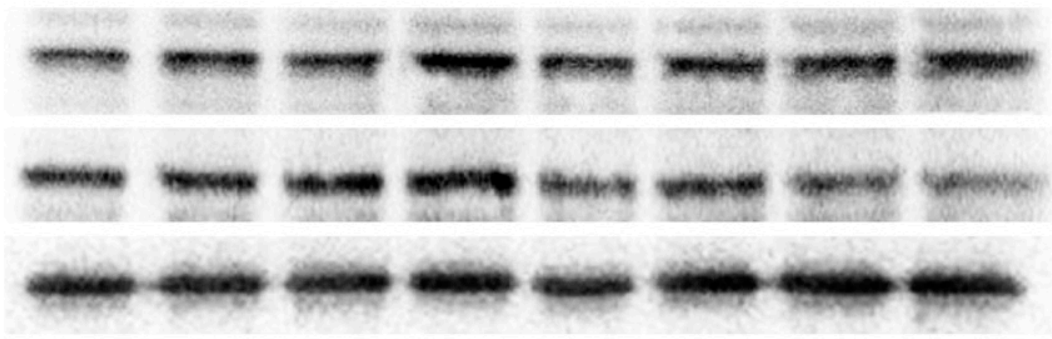

B
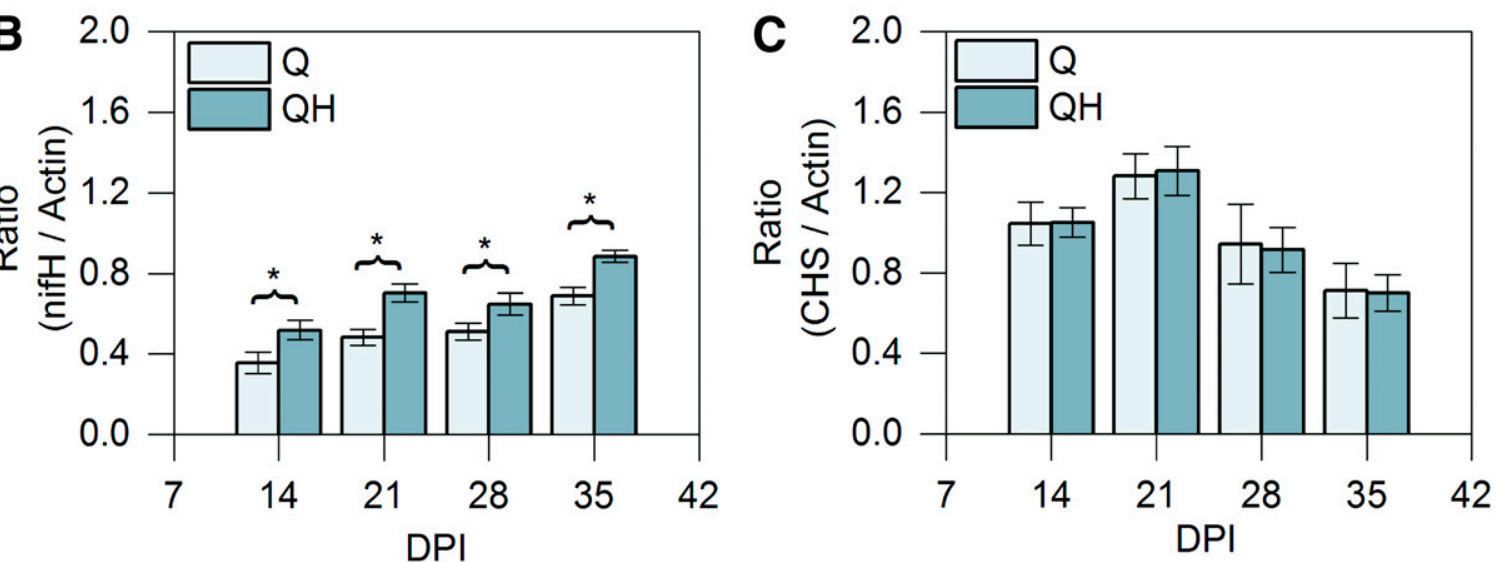

Fig. 7. A, Western blotting analysis of the expression of the nitrogenase iron protein (nifH) and chalcone synthase (CHS) in soybean nodules at $14,21,28$, and 35 days postinoculation (DPI). Expression levels of $\mathbf{B}$, nifH and $\mathbf{C}, \mathrm{CHS}$ are relative to actin. An asterisk $(*)$ indicates significant difference $(P<0.05)$. $\mathrm{Q}=$ soybean seedlings inoculated with Sinorhizobium fredii Q8 strain and QH = soybean seedlings inoculated with $S$. fredii $\mathrm{Q} 8$ strain and treated with $100 \mu \mathrm{M}$ sodium hydrosulfide. Values are means \pm standard error $(n=9)$. 
promote the bacterial infection in the nodulation process, and may enhance the colonization of $S$. fredii into soybean nodules.

Baudouin et al. (2006) demonstrated that NO is synthesized in $M$. truncatula nodules and is required for nodule functioning, and Leach et al. (2010) used NO synthase-specific inhibitors to show that NO is crucial for the development of functional nodules in soybean. In our current study, both paraffin section observation and TEM were conducted to explore whether $\mathrm{H}_{2} \mathrm{~S}$ could cause any structural change in soybean root nodules. According to the paraffin section observation, NaHS treatment did not cause any significant structural change in soybean nodules. As for TEM, the ultrastructure of soybean nodules was also not significantly affected by $\mathrm{H}_{2} \mathrm{~S}$. The bacteroids in the infected cells exhibited typical characteristics in both NaHStreated nodules and control nodules. Together, these results suggested that $\mathrm{H}_{2} \mathrm{~S}$ may not have significant effect on morphogenesis during the nodulation process, and it may promote Nase activity through other mechanism.
$\mathrm{H}_{2} \mathrm{~S}$ promotes photosynthetic and photochemical activity in soybean plants.

Herein, we demonstrated the regulatory role of $\mathrm{H}_{2} \mathrm{~S}$ in symbiosis, nitrogen fixation, and metabolism in the soybeanrhizobia symbiotic system. In plants, adequate nitrogen content can positively affect many physiological processes such as flowering, carbon assimilation in tissues, and ion uptake (Fernandes and Rossiello 1995; Xu et al. 2001). In plants, nitrogen content is closely related to chlorophyll content and photosynthesis in leaves (Gulmon and Chu 1981; Lapointe 1987), because nitrogen is a component of chlorophyll and photosynthesis-related proteins. Therefore, nitrogen content in soybean plants may influence the formation of chloroplasts and accumulation of chlorophyll in them. In this work, both chlorophyll content and Pn were elevated in leaves of NaHS-treated plants (Fig. 5). The soybean plants were cultured in perlitevermiculite substrate and watered with nitrogen-free nutrient solution in our study, which caused nitrogen starvation during
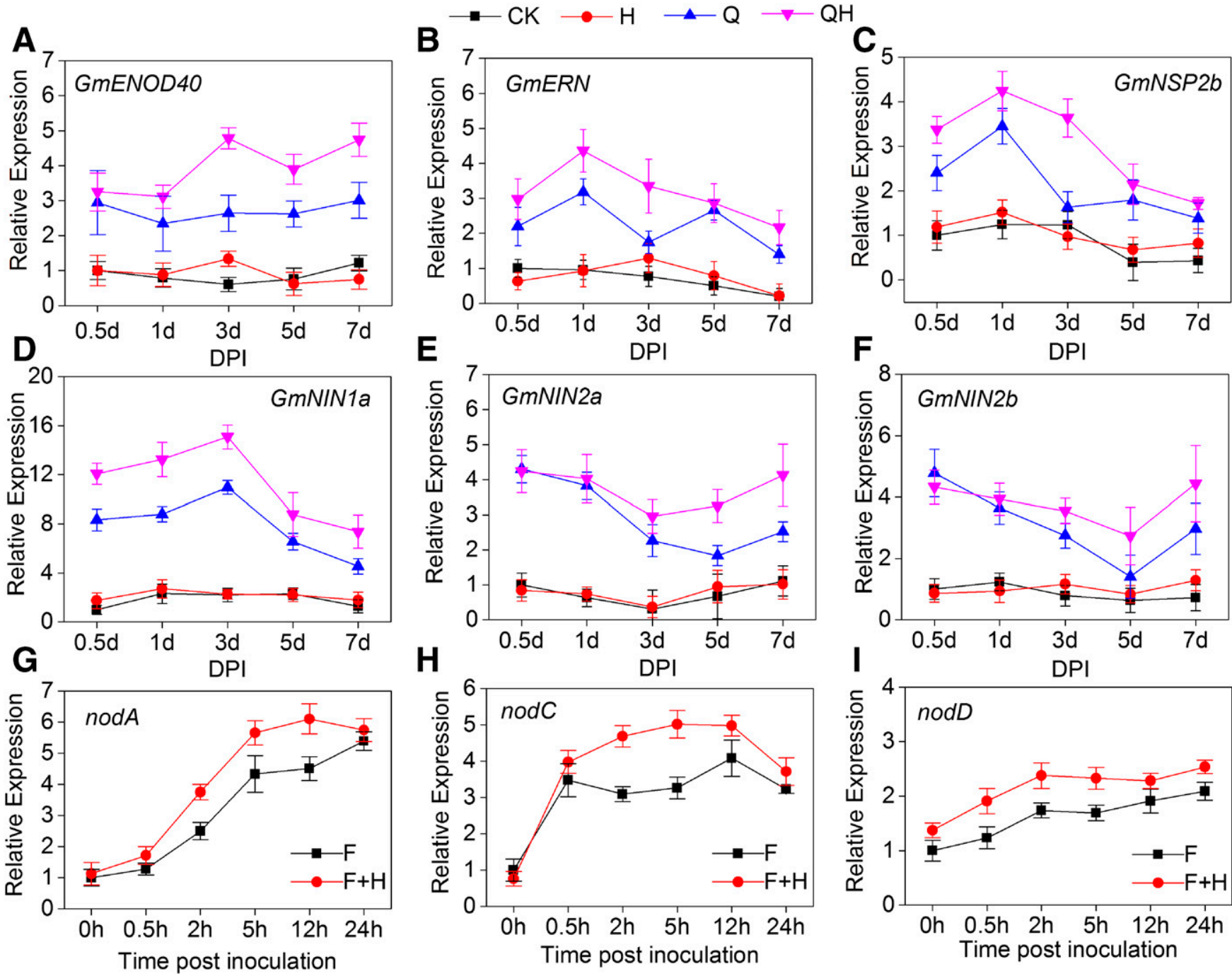

Fig. 8. Gene expression level of symbiotic related genes. Relative expression levels of genes A, GmENOD40; B, GmERN; C, GmNSP2b; D, GmNIN1a; E, GmNIN $2 a ; \mathbf{F}, G m N I N 2 b ; \mathbf{G}, \operatorname{nod} A ; \mathbf{H}, \operatorname{nod} C$; and $\mathbf{I}, \operatorname{nodD}$ are displayed in multiple line charts with symbols. CK $=$ controls, $\mathrm{H}=$ soybean plants treated with $100 \mu \mathrm{M}$ sodium hydrosulfide (NaHS), Q = soybean plants inoculated with the Sinorhizobium fredii Q8 strain, QH = Soybean plants inoculated with the $S$. fredii Q8 strain and treated with $100 \mu \mathrm{M}$ NaHS, $\mathrm{F}=S$. fredii treated with exogenous flavonoids, and $\mathrm{F}+\mathrm{H}=S$. fredii treated with exogenous flavonoids and $100 \mu \mathrm{M}$ NaHS. Expression levels of genes GmENOD40, GmERN, GmNSP2b, and GmNIN were relative to the expression level of respective genes in CK roots at 0.5 days postinoculation (DPI). Expression levels of nodA, nodC, and nodD were relative to the expression level of respective genes in $\mathrm{F}$ rhizobia at 0 h. The $16 s$ ribosomal RNA gene and Gmactin were used as endogenous control to normalize the quantification of transcript abundances in Sinorhizobium fredii and Glycine max, respectively. Values are means \pm standard error of three biological replicates and three technical replicates $(n=9)$. 
plant growth. Because $\mathrm{H}_{2} \mathrm{~S}$ may promote soybean nodulation and nitrogen fixation ability, it may have increased the nitrogen supplement in the soybean plants, which eventually alleviated nitrogen starvation and increased chlorophyll content and Pn in the NaHS-treated soybean plants. Although $\mathrm{H}_{2} \mathrm{~S}$ significantly increased the chlorophyll content in the soybean leaves, it did not significantly affect the $\mathrm{NH}_{4}{ }^{+}$and $\mathrm{NO}_{3}^{-}$concentration in soybean roots and shoots (Supplementary Fig. S5). This result is understandable: that, under nitrogen deficiency conditions, limited nitrogen in plant tissues will be rapidly transformed into organic compounds.

$\mathrm{H}_{2} \mathrm{~S}$ also acted as a modulator of PSII activity in soybean. Specifically, PSII, Fv/Fm, and $\mathrm{Fv}^{\prime} / \mathrm{Fm}^{\prime}$ parameters in inoculated plants were increased (Fig. 6), indicating that the photochemical efficiency in the NaHS-treated soybean leaves was increased. This is consistent with the increase in chlorophyll content caused by $100 \mu \mathrm{M}$ NaHS treatment. Together with increased chlorophyll content and PSII activity, this enhanced photosynthesis led to higher carbon assimilation and, ultimately, promoted the soybean plant growth and symbiotic relationship between soybean and rhizobia.

\section{$\mathrm{H}_{2} \mathrm{~S}$ regulates the expression of genes and proteins related to symbiosis and nitrogen metabolism.}

After analysis at the phenotypic level, we sought to elucidate the effects of $\mathrm{H}_{2} \mathrm{~S}$ on the expression of genes and proteins related to symbiosis and nitrogen fixation in the soybeanrhizobia system. First, we focused on Nase, the enzyme which catalyzes the nitrogen-fixation process. The Nase complex consists of two metalloproteins that are highly conserved in sequence and structure throughout nitrogen-fixing bacteria (Halbleib and Ludden 2000). One protein component contains the active site for substrate reduction with a molybdenum-iron (MoFe) cofactor, while the other iron $(\mathrm{Fe})$-containing protein acts as election donor to the MoFe component (Roth et al. 2010). The Fe protein is a $64-\mathrm{kDa} \alpha_{2}$ dimer of the nifH gene product (Halbleib and Ludden 2000). In this research, we detected the nifH protein as an indicator for Nase content using Western blotting analysis. The results showed that the abundance of the nifH protein was increased by NaHS treatment (Fig. 7A and B).

Then, we determined the content of CHS, an enzyme catalyzing the synthesis of chalcone, which is reported to be a key precursor of a series of flavonoids (Dao et al. 2011; Schijlen et al. 2007). Li et al. (1993) demonstrated that CHS-deficient Arabidopsis displayed lower production of flavonoids. In the present study, the results of Western blotting analysis showed that the abundances of CHS in root nodules were not affected by $\mathrm{H}_{2} \mathrm{~S}$ (Fig. 7A and C). This result suggested that $\mathrm{H}_{2} \mathrm{~S}$ may not regulate soybean nodulation via early signaling recognition between soybean and rhizobia.

Then, we investigated the expression of genes related to symbiosis and nitrogen metabolism in root nodules. GmENOD40 was reported to be the downstream component of the perception of Nod factors (NFs) (Ferguson et al. 2010), which is expressed in pericycle cells of root vascular bundles, dividing cortical cells, the nodule primordium, and developing nodules (Ferguson and Mathesius 2014). Charon et al. (1999) reported that alteration in the expression of ENOD40 could influence nodulation, suggesting that it plays a vital role in nodule organogenesis. In the present study, expression of gene $G m E$ NOD4O in soybean was upregulated by NaHS treatment (Fig. 8A). NIN is essential for nodule organogenesis and is also required for the initiation of bacterial infection in the roots
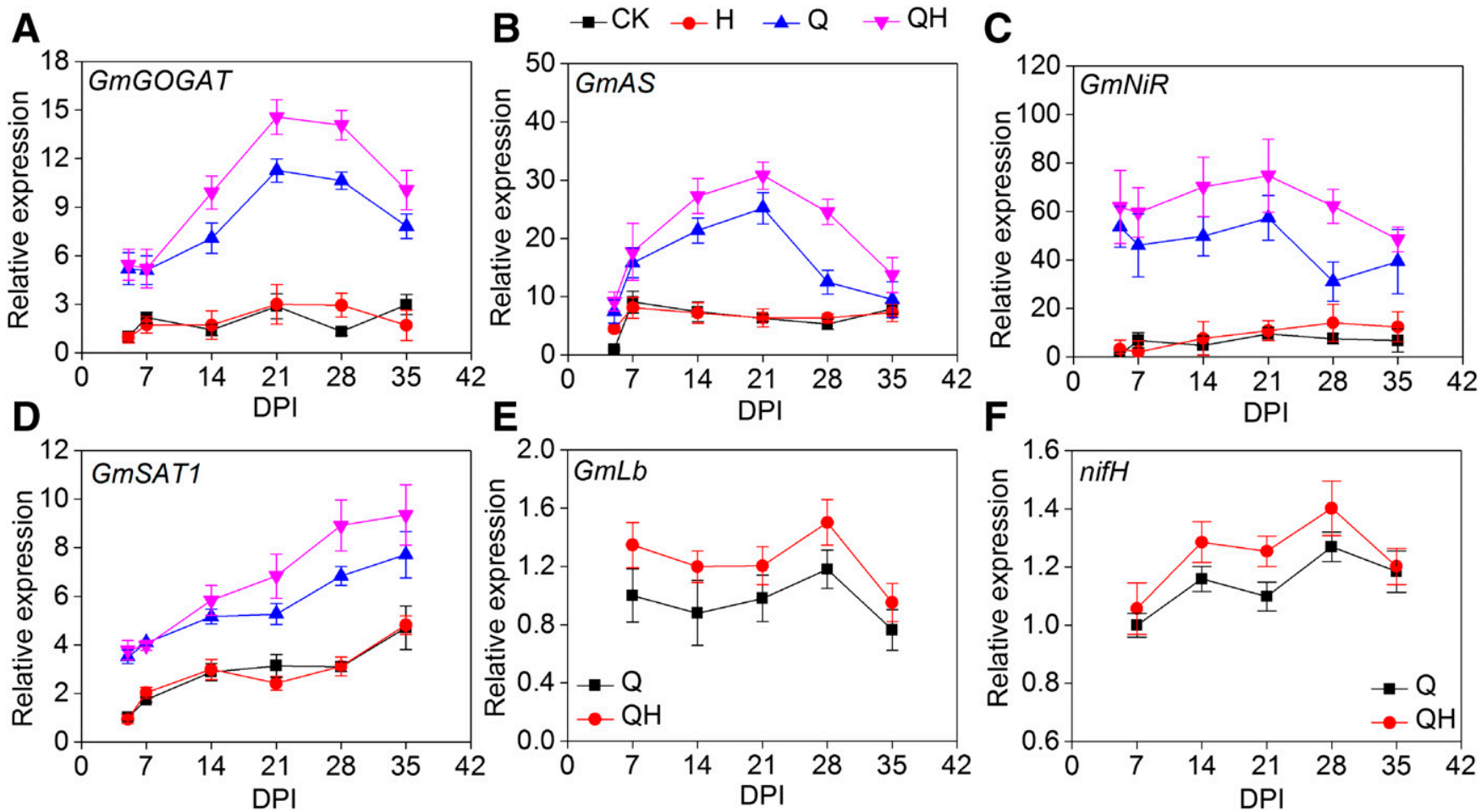

Fig. 9. Gene expression level of nitrogen-metabolism related genes. Relative expression levels of A, GmGOGAT; B, GmAS; C, GmNiR; D, GmSAT1; E, GmLb; and $\mathbf{F}$, nifH are displayed in multiple-line charts with symbols. $\mathrm{CK}=$ controls, $\mathrm{H}=$ soybean plants treated with $100 \mu \mathrm{M}$ sodium hydrosulfide $(\mathrm{NaHS}), \mathrm{Q}=$ soybean plants inoculated with the Sinorhizobium fredii Q8 strain, and QH = soybean plants inoculated with the Sinorhizobium fredii Q8 strain and treated with $100 \mu \mathrm{M}$ NaHS. Expression levels of genes GmGOGAT, GmAS, GmNiR, and GmSAT1 were relative to the expression levels of respective genes in CK roots at 5 days postinoculation (DPI). Expression levels of $G m L b$ and nifH were relative to the expression levels of respective genes in Q nodules at 7 DPI. The $16 s$ ribosomal RNA gene and Gmactin were used as endogenous control genes to normalize the quantification of transcript abundances in Sinorhizobium fredii and Glycine max, respectively. Values are means \pm standard error of three biological replicates and three technical replicates $(n=9)$. 
(Madsen et al. 2010; Vernié et al. 2015). In this case, the expression levels of three NIN genes in soybean were upregulated by NaHS treatment (Fig. 8D, E, and F). In addition, the other two nodulation marker genes involved in the NF nodulation pathway (GmERN and GmNSP2b) were also activated in the NaHStreated soybean roots (Fig. $8 \mathrm{~B}$ and C). Together, the present results suggested that $\mathrm{H}_{2} \mathrm{~S}$ upregulated the expression of $\mathrm{GmE}$ NOD40, GmERN, GmNSP2b, and GmNIN genes, which play a crucial role in the NF nodulation signaling pathway and are closely related to the organogenesis and development of root nodules. These results may have indicated that NaHS promoted soybean nodulation and nodule development through regulating the expression abundance of symbiotic-related genes.

On the bacterial side, nod genes in rhizobia are crucial for the early stages of recognition by legume hosts because they encode host-specific lipochito-oligosaccharidic NFs that can activate downstream symbiotic reactions by binding to plant kinase-like receptors (Giraud et al. 2007). Among the nod genes, nodD is a key player because, after sensing flavonoid signals secreted by legume roots into the soil, nodD initiates the expression of other nod genes (Machado and Krishnan 2003). The results of qRT-PCR demonstrated that transcript abundances of nodA, nodC, and nodD genes were increased in freeliving $S$. fredii, suggesting that $\mathrm{H}_{2} \mathrm{~S}$ not only promotes symbiosis by affecting the legume host but also triggers stronger symbiotic responses in the rhizobia.

Uptake of nitrate by root cells followed by reduction and assimilation in plant tissues is the main route by which mineral nitrogen is converted into organic nitrogen by living organisms. Like photosynthesis, these are life-dependent processes (Imsande and Touraine 1994). In our study, the relative expression levels of six genes related to nitrogen metabolism, including soybean genes GmGOGAT, GmAS, GmNiR, GmSATl, GmLb, and rhizobial gene nifH, were quantified by qRT-PCR (Fig. 9). These genes encode crucial players in amino acid metabolism and nitrogen assimilation. Expression of GmGOGAT, GmAS, GmNiR, and GmSAT1 was strongly induced by $\mathrm{H}_{2} \mathrm{~S}$ compared with untreated controls (Fig. 9). Glutamic acid and aspartic acid are two essential amino acids that provide carbon skeletons for the synthesis of many amino acids by transamination. Indeed, $\delta$-aminolevulinic acid, a precursor of chlorophyll, is synthesized from the intact carbon skeleton of glutamic acid (Beale 1990). Furthermore, asparagine is the common precursor of the essential amino acids lysine, threonine, methionine, and isoleucine in higher plants, and aspartate may also be converted to asparagine in a potentially competing reaction (Azevedo et al. 2006). The ammonium transporter encoded by GmSAT1 was reported to be located in the peribacteroid membrane, and is believed to be responsible for the transportation of ammonium fixed by bacteroids in soybean nodules (Kaiser et al. 1998). Thus, upregulation of GmGOGAT, $G m A S$, and GmSATl indicates that $\mathrm{H}_{2} \mathrm{~S}$ might enhance the transportation of fixed ammonium and its assimilation into amino acids (Fig. 9A, B, and D). In addition, nitrate assimilation can occur in either the roots or leaves via the nitrate reductase-nitrite reductase pathway (Evans 2001). The product of this assimilation event is $\mathrm{NH}_{4}{ }^{+}$, and assimilation of $\mathrm{NH}_{4}{ }^{+}$occurs through the glutamine synthetase-glutamate synthase pathway. Assimilation occurs in the roots, near the site of uptake, to avoid toxic accumulation (Bloom 1988). Therefore, we can conclude that $\mathrm{H}_{2} \mathrm{~S}$ upregulated the expression of GmGOGAT, GmAS, GmNiR and GmSAT1 genes, through which led to higher $\mathrm{N}$ supply to the soybean plants (Fig. 9).

Leghemoglobin ( $\mathrm{Lb}$ ) is one of the main functional components that provides an optimal environment for the nitrogenfixation process in root nodules. The main function of $\mathrm{Lb}$ is to supply oxygen to the bacteroids, to support the respiration during nitrogen fixation at a low concentration to avoid disrupting Nase, which is highly sensitive to oxygen (Marino et al. 2013). Thus, the upregulated expression of gene $G m L b$ may provoke a positive alteration in the redox environment in soybean nodules which will finally lead to higher nitrogen fixation (Fig. 9E). Moreover, NaHS treatment increased the transcription abundance of nifH during the treatment (Fig. 9F). Together with the results of Western blot analysis, these results indicated that the NaHS treatment promoted the Nase activity through upregulating the expression of the nifH gene and increasing Fe protein content in soybean root nodules.

According to our results, we hypothesized a model to explain the stimulatory effects of $\mathrm{H}_{2} \mathrm{~S}$ on symbiosis. $\mathrm{H}_{2} \mathrm{~S}$ may promote soybean nodulation through upregulating the expression of symbiosis-related genes in both plants and rhizobia (Fig. 10). Meanwhile, the nitrogen fixation was also enhanced by $\mathrm{H}_{2} \mathrm{~S}$ because it may upregulate the synthesis of nifH protein in root nodules and promote Nase activity. Moreover, $\mathrm{H}_{2} \mathrm{~S}$ also stimulated the expression of nitrogen-metabolism-related genes and led to higher nitrogen assimilation. This elevated nitrogen supply increased the chlorophyll synthesis and promoted photosynthesis in soybean leaves, which eventually led to soybean growth promotion..

\section{Conclusion.}

In this study, we demonstrated the potential role of $\mathrm{H}_{2} \mathrm{~S}$ in symbiosis and nitrogen fixation in the G. $\max -S$. fredii symbiotic system. Our results suggested that $\mathrm{H}_{2} \mathrm{~S}$ enhances the symbiotic relationship of $G$. max $-S$. fredii because NaHS treatment promoted nodulation and Nase activity in soybean. In addition, $\mathrm{H}_{2} \mathrm{~S}$ promoted infection of rhizobia in both roots and nodules of soybean by upregulating the expression of symbiosisrelated genes such as GmENOD40, GmERN, GmNSP2b, $G m N I N, \operatorname{nod} A, \operatorname{nod} C$, and $\operatorname{nod} D$. Additionally, the abundance of nifH protein was increased in soybean nodules following NaHS treatment. Moreover, NaHS treatment stimulated the expression of nitrogen-metabolism-related genes such as GmGOGAT, GmAs, GmNiR, GmSAT1, GmLb, and nifH. The enhanced nitrogen fixation and assimilation increased the chlorophyll content, the Pn, and PSII activity in inoculated plants. Finally, this enhanced photosynthesis endowed soybean plants with promoted growth. Taken together, these findings suggested that $\mathrm{H}_{2} \mathrm{~S}$

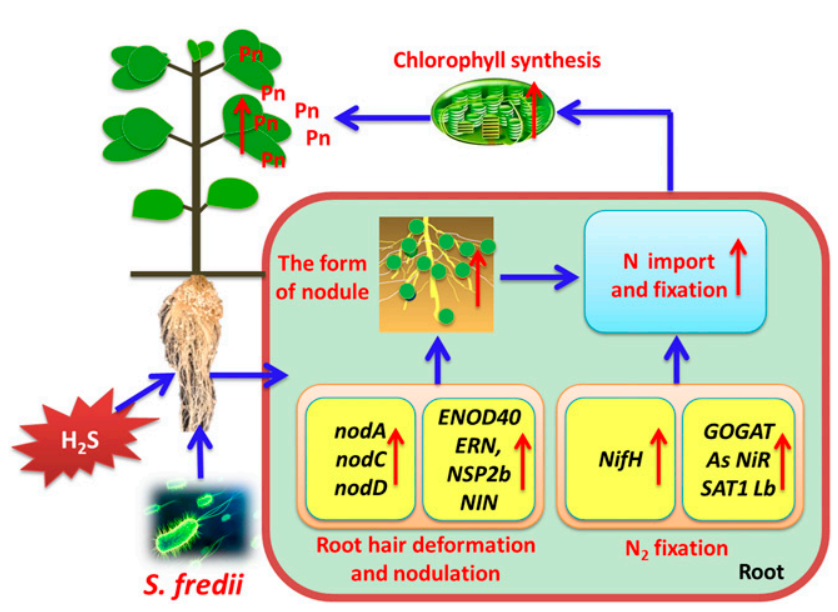

Fig. 10. Schematic model of the mechanisms underlying the positive effects of hydrogen sulfide $\left(\mathrm{H}_{2} \mathrm{~S}\right)$ on the Glycine max-Sinorhizobium fredii symbiotic system. The model, based on the results of the present study and the wider literature, explains how exogenous $\mathrm{H}_{2} \mathrm{~S}$ might influence the nodulation signaling pathway and the biological nitrogen fixation capacity in G. $\max$. $\mathrm{Pn}=$ net photosynthetic rate. Arrows within smaller boxes indicate promotion effect. Arrows between and outside of the boxes indicate interactions. 
promoted soybean growth under symbiotic conditions by enhancing the establishment of symbiosis and stimulating nitrogen fixation in the G. max-S. fredii symbiotic system. Further details of the underlying molecular and physiological mechanisms such as the targets of $\mathrm{H}_{2} \mathrm{~S}$, and how $\mathrm{H}_{2} \mathrm{~S}$ fits into regulatory signaling pathways still need further study.

\section{MATERIALS AND METHODS}

\section{Plant growth and $\mathrm{H}_{2} \mathrm{~S}$ treatment.}

Soybean (G. max 'Zhonghuang 13') seed were surface sterilized with $75 \%$ ethyl alcohol and sodium hypochlorite, then placed on a $1 \%$ agar plate for $72 \mathrm{~h}$ at $28^{\circ} \mathrm{C}$ in the dark. Growth medium $(800 \mathrm{ml})$ (vermiculite-perlite, 1:1 [vol/vol]) was watered with $400 \mathrm{ml}$ of nitrogen-free nutrient solution $\left(\mathrm{CaCl}_{2}\right.$ at $100 \mathrm{mg} / \mathrm{liter}$, $\mathrm{KH}_{2} \mathrm{PO}_{4}$ at $100 \mathrm{mg} /$ liter, Ferric citrate at $5 \mathrm{mg} /$ liter, $\mathrm{NaH}_{2} \mathrm{PO}_{4}$ at $150 \mathrm{mg} /$ liter, $\mathrm{MgSO}_{4}$ at $240 \mathrm{mg} / \mathrm{liter}, \mathrm{H}_{3} \mathrm{BO}_{3}$ at $2.86 \mathrm{mg} / \mathrm{liter}$, $\mathrm{MnSO}_{4} \cdot 4 \mathrm{H}_{2} \mathrm{O}$ at $2.03 \mathrm{mg} / \mathrm{liter}, \mathrm{ZnSO}_{4} \cdot 7 \mathrm{H}_{2} \mathrm{O}$ at $0.22 \mathrm{mg} / \mathrm{liter}$, $\mathrm{Na}_{2} \mathrm{MoO}_{4} \cdot 2 \mathrm{H}_{2} \mathrm{O}$ at $0.06 \mathrm{mg} / \mathrm{liter}$, and $\mathrm{CuSO}_{4} \cdot 5 \mathrm{H}_{2} \mathrm{O}$ at $0.08 \mathrm{mg} / \mathrm{liter}$ ) and sterilized in a polypropylene planting bag. Germinated seed were transferred into growth medium (one seeding/bag). Seven-day-old soybean seedlings were divided into four groups: the first group served as controls, the second group was treated with $100 \mu \mathrm{M} \operatorname{NaHS}(\mathrm{H})$, the third group was inoculated with rhizobia (S. fredii Q8 strain) $(\mathrm{Q})$, and fourth group inoculated with $S$. fredii and treated with NaHS $(\mathrm{QH})$. All seedlings in the Q and $\mathrm{QH}$ groups were inoculated with $10 \mathrm{ml}$ of a rhizobial suspension (optical density at $600 \mathrm{~nm}\left[\mathrm{OD}_{600}\right]=0.05$ ) 10 days after sowing. NaHS was used as the $\mathrm{H}_{2} \mathrm{~S}$ donor (Christou et al. 2013). Seedlings in the $\mathrm{H}$ and $\mathrm{QH}$ groups were watered with $10 \mathrm{ml}$ of NaHS solution $(100 \mu \mathrm{M})$ every 3 days until harvest, and seedlings from the other two groups were watered with double-distilled $\mathrm{H}_{2} \mathrm{O}$ instead. Sterile nitrogen-free nutrient solution $(50 \mathrm{ml})$ was added to each bag every 7 days to maintain the steady humidity and ionic concentration. Seedlings from each treatment were harvested every 7 days since inoculation, and half of the samples were dried to a constant weight for dry matter determination while the other half was immediately frozen in liquid nitrogen and stored at $-80^{\circ} \mathrm{C}$. We grew a total of four sets of soybean seedlings at different times as four replicates.

\section{Root length, shoot length, root weight, and shoot weight measurements.}

The longest distance of root or shoot tip to the junction of root and hypocotyl were set as root length and shoot length. Five soybean seedlings of each treatment group were harvested every 7 days after inoculation for these measurements, and this experiment was repeated four times with four sets of soybean plants as biological replicates.

\section{Nase activity determination.}

Nase activity was quantified using the acetylene reduction method of Fishbeck et al. (1973), with slight modifications. Fresh soybean root nodules were transferred into a $10-\mathrm{ml}$ rubber-capped airtight glass bottle filled with a mixture of acetylene and air $(1: 100[\mathrm{vol} / \mathrm{vol}])$. Bottles were incubated at $28^{\circ} \mathrm{C}$ for $3 \mathrm{~h}$, and the content of ethylene was determined using a gas chromatography system (Agilent Technologies, La Jolla, CA, U.S.A.). Standard curves made by pure ethylene standard sample were used to calibrate the result of gas chromatography.

\section{Infection event assay.}

The $S$. fredii Q8 strain harboring the enhanced green fluorescence protein encoded on the pMP2444 plasmid was employed. The plasmid was incorporated into the Q8 strain by triparent hybridization through the assistant plasmid pRK2013
(Nishikawa et al. 2008). We define the 2-cm segment below the root-hypocotyl junction as the infection zone as described by Wang et al. (2014), because most nodules appeared in this part of the root. All of the lateral roots from this segment were cut and observed, and typical infection events were determined at 5 and 7 DPI using a BX53 fluorescence microscope (Olympus, Tokyo, Japan). This experiment was repeated for four times with biological replicates.

\section{Visualization of $\mathrm{H}_{2} \mathrm{~S}$ with fluorescent probe SF7-AM and $\mathrm{H}_{2} \mathrm{~S}$ content quantification.}

$\mathrm{H}_{2} \mathrm{~S}$ fluorescent probe SF7-AM was purchased from SigmaAldrich (CAS: 1416872-50-8; Dallas, TX, U.S.A.). The experiment was performed on entire roots and fresh nodule slices $(100 \mu \mathrm{m})$ obtained with a freezing microtome (Tissue-Tek, Sakura, Japan). As described by Lin et al. (2013), plant tissues were washed with phosphate buffer $(\mathrm{pH}=7.4)$, then incubated in $5 \mathrm{mM}$ SF7-AM for $1 \mathrm{~h}$, washed with $20 \mathrm{mM}$ HEPES, and visualized and photographed using a BX53 fluorescence microscope (Olympus). The fluorescence intensity was quantified by ImageJ software (National Institutes of Health, Bethesda, MD, U.S.A.)

The endogenous $\mathrm{H}_{2} \mathrm{~S}$ content was assayed using the methylene blue method described by Zhang et al. (2008). The calibration curve was made with NaHS solution concentrations. Plant tissues were collected at $14 \mathrm{DPI}$. The $\mathrm{H}_{2} \mathrm{~S}$ content was expressed on a fresh weight basis (micromoles per kilogram). This experiment was repeated three times with biological replicates.

\section{Chlorophyll content determination.}

Measurement of the chlorophyll content in soybean seedlings was carried out using a SPAD-502 Plus leaf chlorophyll meter (Konica Minolta, Kumamoto, Japan). In total, 10 leaves (third fully developed leaf) from 5 soybean seedlings per treatment were measured at 10:00 A.M. every 7 days until harvest. This experiment was repeated two times with biological replicates.

\section{Determination of photosynthesis} and chlorophyll fluorescence parameters.

Pn was measured using a portable photosynthesis system ( $\mathrm{Li}$ 6400; Li-Cor, Lincoln, NE, U.S.A.) on the second fully expanded leaf of a soybean seedling. In all, 10 different leaves from five different soybean seedlings were tested, and the measurement was conducted twice. Air temperature, light intensity, $\mathrm{CO}_{2}$ concentration, and air relative humidity were maintained at $25^{\circ} \mathrm{C}, 800 \mu \mathrm{mol} \mathrm{m} \mathrm{s}^{-2}$ photosynthetically active radiation, $380 \mu 11^{-1}$, and $90 \%$, respectively. Determination was conducted from 9:00 to 11:00 A.M. to avoid high temperature and air vapor pressure deficits. Light was supplemented using an LED light system. Vapor pressure deficit during measurement was approximately $1 \mathrm{kPa}$.

Chlorophyll fluorescence measurement was conducted on 10 leaves (third fully developed leaf) from five soybean seedlings using a Plant Efficiency Analyzer (Hansatech Instruments Ltd., Norfolk, England). Before measurement, leaves were pretreated in the dark for $30 \mathrm{~min}$. Minimal fluorescence (Fo), maximal fluorescence $(\mathrm{Fm}), \mathrm{Fv}(=\mathrm{Fm}-\mathrm{Fo})$, and Fv/Fm parameters were recorded for $15 \mathrm{~s}$ at a photon flux density of $4,000 \mu \mathrm{mol} \mathrm{m} \mathrm{s}^{-2}$. Additionally, we measured the steady-state fluorescence level $\left(\mathrm{Fs}^{\prime}\right)$ under continuous illumination, the maximal fluorescence level $\left(\mathrm{Fm}^{\prime}\right)$ induced by a saturating light pulse at the steady state, and the minimum fluorescence level $\left(\mathrm{Fo}^{\prime}\right)$ after exposure to far-red light for $3 \mathrm{~s}$. Then, $\mathrm{Fv}^{\prime}$ was calculated using the formula $\mathrm{Fv}^{\prime}=\mathrm{Fm}^{\prime}-\mathrm{Fo}^{\prime}$. PSII was calculated using the formula PSII $=1-\left(\mathrm{Fs}^{\prime} / \mathrm{Fm}^{\prime}\right)$. This experiment was repeated twice. 


\section{Sodium dodecyl sulfate-polyacrylamide} gel electrophoresis and Western blotting assays.

Total protein of soybean samples was extracted following the protocol of Chen et al. (2011). After total protein isolation, protein concentrations were quantified using the Bradford (1976).

For Western blotting analysis, proteins ( $200 \mu \mathrm{g}$ for each sample) were separated by sodium dodecyl sulfate-polyacrylamide gel electrophoresis using $12 \%$ acrylamide gels and transferred to a polyvinylidene difluoride membrane. The membrane was blocked overnight with 5\% skim milk powder. Protein blots were probed with primary antibodies for nifH (1:2000, AS01 021A; Agrisera, Vännäs, Sweden) or CHS (1:1000, AS12 2615; Agrisera) at a dilution of 1:5000 or 1:3000, respectively, at $4^{\circ} \mathrm{C}$ overnight. Blots were washed three times in a solution of $50 \mathrm{mM}$ TRIS- $\mathrm{HCl}(\mathrm{pH}$ 8.0), $150 \mathrm{mM} \mathrm{NaCl}$, and $0.05 \%$ Tween-20, followed by incubation with secondary antibody (antirabbit immunoglobulin G horseradish peroxidase-conjugated, 1:5000 dilution; Sungene, Tianjin, China) overnight at $4^{\circ} \mathrm{C}$. Actin (1:5000, AS13 2640; Agrisera) was used as an internal control. Blots were finally washed with phosphate-buffered saline-Tween three times, and imaged using a Molecular Imager Gel Doc XR System (Bio-Rad, Hercules, CA, U.S.A.). The OD value was determined using Image $J$ software and used to estimate the protein abundance. This experiment was conducted with three biological replicates.

\section{Exogenous flavonoids treatment.}

TY liquid medium ( $30 \mathrm{ml}$ of tryptone at $5 \mathrm{~g} /$ liter, yeast extract at $3 \mathrm{~g} /$ liter, and $\mathrm{CaCl}_{2}$ at $0.5 \mathrm{~g} /$ liter) was inoculated with $20 \mu \mathrm{l}$ of $S$. fredii preserved in $30 \%$ glycerin $\left(\mathrm{OD}_{600}=0.1\right)$. The medium was then shake cultured (200 rpm) for $24 \mathrm{~h}$ at $28^{\circ} \mathrm{C}$. Glycitein and genistein were made into a $15-\mathrm{mg} / \mathrm{ml}$ stock solution and sterilized by filtration. Each stock solution $(30 \mu \mathrm{l})$ was then added to the medium (final concentration $=15 \mu \mathrm{g} / \mathrm{ml}$ ). After $0,0.5,2.5,5,12$, and $24 \mathrm{~h}$ of shake culture (200 rpm) at $28^{\circ} \mathrm{C}$, rhizobia samples were collected for RNA extraction.

\section{Total RNA isolation, reverse transcription, and gene expression analysis.}

Total RNA isolation was performed using the TaKaRa MiniBEST Plant RNA Extraction Kit (TaKaRa, Beijing, China) according to the manufacturer's instructions. RNA integrity was examined by $1 \%$ agarose gel electrophoresis. RNA concentration was determined using an Epoch Microplate Spectrophotometer (BioTek, Winooski, VT, U.S.A.). Reverse transcription was conducted using TaKaRa PrimerScript TM RT master Mix (TaKaRa) as suggested by the manufacturer. qRT-PCR was carried out with a Quantstudio 6 Flex real-time PCR system (Thermo Fisher, Carlsbad, CA, U.S.A.) and SYBR Premix Ex Taq II (TaKaRa). The qPCR programs are described in Supplementary Table S2. Primers used for expression assay were designed with Primer Premier 5.0 software (Premier Biosoft International, Palo Alto, CA, U.S.A.) according to the coding sequences (CDS) of the respective genes. The CDS of the genes were obtained from GenBank or EMBL. Target fragments amplified by the primers were sequenced and checked by agarose gel to ensure the accuracy of the qRT-PCR reaction. The sequences of the primers used in the present study are listed in Supplementary Table S1. The 16 s ribosomal RNA gene and Gmactin were used as endogenous control genes to normalize the quantification of transcript abundances in $S$. fredii and G. max, respectively. qRT-PCR was conducted with three biological replicates and three technical replicates.

\section{Statistical analysis.}

Statistical significance was tested by ANOVA using SPSS 19.0 (SPSS Inc., Chicago, IL, U.S.A.). All of the significances in time course experiments were tested using the RM ANOVA of GLM; for these parametric tests, differences were considered statistically significant at $P<0.05$.

\section{ACKNOWLEDGMENTS}

We thank Y.-T. Luo, M.-M. Lu, and J.-Q. Liang for guidance on experimental methods; and S. Jiao has provided constructive suggestions to the writing of this article.

\section{LITERATURE CITED}

Álvarez, C., García, I., Moreno, I., Pérez-Pérez, M. E., Crespo, J. L., Romero, L. C., and Gotor, C. 2012. Cysteine-generated sulfide in the cytosol negatively regulates autophagy and modulates the transcriptional profile in Arabidopsis. Plant Cell 24:4621-4634.

Azevedo, R. A., Lancien, M., and Lea, P. J. 2006. The aspartic acid metabolic pathway, an exciting and essential pathway in plants. Amino Acids 30:143-162.

Baudouin, E., Pieuchot, L., Engler, G., Pauly, N., and Puppo, A. 2006. Nitric oxide is formed in Medicago truncatula-Sinorhizobium meliloti functional nodules. Mol. Plant-Microbe Interact. 19:970-975.

Beale, S. I. 1990. Biosynthesis of the tetrapyrrole pigment precursor, $\delta$-aminolevulinic acid, from glutamate. Plant Physiol. 93:1273-1279.

Becana, M., and Sprent, J. I. 1987. Nitrogen fixation and nitrate reduction in the root nodules of legumes. Physiol. Plant. 70:757-765.

Bloom, A. J. 1988. Ammonium and nitrate as nitrogen sources for plant growth. Isi Atlas Sci. Anim. Plant Sci. 1:55-59.

Bradford, M. M. 1976. A rapid and sensitive method for the quantitation of microgram quantities of protein utilizing the principle of protein-dye binding. Anal. Biochem. 72:248-254.

Caballero-Mellado, J., and Martinez-Romero, E. 1999. Soil fertilization limits the genetic diversity of Rhizobium in bean nodules. Symbiosis 26 : 111-121.

Cam, Y., Pierre, O., Boncompagni, E., Hérouart, D., Meilhoc, E., and Bruand, C. 2012. Nitric oxide (NO): A key player in the senescence of Medicago truncatula root nodules. New Phytol. 196:548-560.

Chandra, N., and Pandey, N. 2016. Role of sulfur nutrition in plant and seed metabolism of Glycine max L. J. Plant Nutr. 39:1103-1111.

Charon, C., Sousa, C., Crespi, M., and Kondorosi, A. 1999. Alteration of enod40 expression modifies Medicago truncatula root nodule development induced by Sinorhizobium meliloti. Plant Cell 11:19531966.

Chen, J., Shang, Y. T., Wang, W. H., Chen, X. Y., He, E. M., Zheng, H. L., and Shangguan, Z. 2016. Hydrogen sulfide-mediated polyamines and sugar changes are involved in hydrogen sulfide-induced drought tolerance in Spinacia oleracea seedlings. Front. Plant Sci. 7:1173.

Chen, J., Wang, W. H., Wu, F. H., You, C. Y., Liu, T. W., Dong, X. J., He, J. X., and Zheng, H. L. 2013. Hydrogen sulfide alleviates aluminum toxicity in barley seedlings. Plant Soil 362:301-318.

Chen, J., Wu, F. H., Wang, W. H., Zheng, C. J., Lin, G. H., Dong, X. J., He, J. X., Pei, Z. M., and Zheng, H. L. 2011. Hydrogen sulphide enhances photosynthesis through promoting chloroplast biogenesis, photosynthetic enzyme expression, and thiol redox modification in Spinacia oleracea seedlings. J. Exp. Bot. 62:4481-4493.

Christou, A., Filippou, P., Manganaris, G. A., and Fotopoulos, V. 2014. Sodium hydrosulfide induces systemic thermotolerance to strawberry plants through transcriptional regulation of heat shock proteins and aquaporin. BMC Plant Biol. 14:42.

Christou, A., Manganaris, G. A., Papadopoulos, I., and Fotopoulos, V. 2013. Hydrogen sulfide induces systemic tolerance to salinity and non-ionic osmotic stress in strawberry plants through modification of reactive species biosynthesis and transcriptional regulation of multiple defence pathways. J. Exp. Bot. 64:1953-1966.

Damiani, I., Pauly, N., Puppo, A., Brouquisse, R., and Boscari, A. 2016. Reactive oxygen species and nitric oxide control early steps of the legume-rhizobium symbiotic interaction. Front. Plant Sci. 7:454.

Dao, T. T., Linthorst, H. J., and Verpoorte, R. 2011. Chalcone synthase and its functions in plant resistance. Phytochem. Rev. 10:397-412.

del Giudice, J., Cam, Y., Damiani, I., Fung-Chat, F., Meilhoc, E., Bruand, C., Brouquisse, R., Puppo, A., and Boscari, A. 2011. Nitric oxide is required for an optimal establishment of the Medicago truncatulaSinorhizobium meliloti symbiosis. New Phytol. 191:405-417.

Dooley, F. D., Nair, S. P., and Ward, P. D. 2013. Increased growth and germination success in plants following hydrogen sulfide administration. PLoS One 8:e62048. 
Evans, R. D. 2001. Physiological mechanisms influencing plant nitrogen isotope composition. Trends Plant Sci. 6:121-126.

Fang, H., Liu, Z., Jin, Z., Zhang, L., Liu, D., and Pei, Y. 2016. An emphasis of hydrogen sulfide-cysteine cycle on enhancing the tolerance to chromium stress in Arabidopsis. Environ. Pollut. 213:870-877.

Ferguson, B. J., Indrasumunar, A., Hayashi, S., Lin, M. H., Lin, Y. H., Reid, D. E., and Gresshoff, P. M. 2010. Molecular analysis of legume nodule development and autoregulation. J. Integr. Plant Biol. 52:61-76.

Ferguson, B. J., and Mathesius, U. 2014. Phytohormone regulation of legume-rhizobia interactions. J. Chem. Ecol. 40:770-790.

Fernandes, M. S., and Rossiello, R. O. P. 1995. Mineral nitrogen in plant physiology and plant nutrition. Crit. Rev. Plant Sci. 14:111-148.

Fishbeck, K., Evans, H. J., and Boersma, L. L. 1973. Measurement of nitrogenase activity of intact legume symbionts in situ using the acetylene reduction assay. Agron. J. 65:429-433.

Fukuto, J. M., Carrington, S. J., Tantillo, D. J., Harrison, J. G., Ignarro, L. J., Freeman, B. A., Chen, A., and Wink, D. A. 2012. Small molecule signaling agents: The integrated chemistry and biochemistry of nitrogen oxides, oxides of carbon, dioxygen, hydrogen sulfide, and their derived species. Chem. Res. Toxicol. 25:769-793.

García-Mata, C., and Lamattina, L. 2010. Hydrogen sulphide, a novel gasotransmitter involved in guard cell signalling. New Phytol. 188: 977-984.

Giraud, E., Moulin, L., Vallenet, D., Barbe, V., Cytryn, E., Avarre, J.-C., Jaubert, M., Simon, D., Cartieaux, F., Prin, Y., Bena, G., Hannibal, L., Fardoux, J., Kojadinovic, M., Vuillet, L., Lajus, A., Cruveiller, S., Rouy, Z., Mangenot, S., Segurens, B., Dossat, C., Franck, W. L., Chang, W. S., Saunders, E., Bruce, D., Richardson, P., Normand, P., Dreyfus, B., Pignol, D., Stacey, G., Emerich, D., Verméglio, A., Médigue, C., and Sadowsky, M. 2007. Legumes symbioses: Absence of nod genes in photosynthetic bradyrhizobia. Science 316:1307-1312.

Gulmon, S. L., and Chu, C. C. 1981. The effects of light and nitrogen on photosynthesis, leaf characteristics, and dry matter allocation in the chaparral shrub, Diplacus aurantiacus. Oecologia 49:207-212.

Halbleib, C. M., and Ludden, P. W. 2000. Regulation of biological nitrogen fixation. J. Nutr. 130:1081-1084.

Hayashi, S., Gresshoff, P. M., and Ferguson, B. J. 2013. Systemic signalling in legume nodulation: Nodule formation and its regulation. Pages 219-229 in: Long-distance systemic signaling and communication in plants, F. Baluška, ed. Springer Berlin.

Hérouart, D., Baudouin, E., Frendo, P., Harrison, J., Santos, R., Jamet, A., Van de Sype, G., Touati, D., and Puppo, A. 2002. Reactive oxygen species, nitric oxide and glutathione: A key role in the establishment of the legume-rhizobium symbiosis? Plant Physiol. Biochem. 40:619-624.

Hichri, I., Boscari, A., Meilhoc, E., Catalá, M., Barreno, E., Bruand, C., Lanfranco, L., and Brouquisse, R. 2016. Nitric oxide: A multitask player in plant-microorganism symbioses. Pages 239-268 in: Gasotransmitters in Plants: The Rise of a New Paradigm in Cell Signaling. L. Lamattina and C. García-Mata, eds. Springer International Publishing, Cham, Switzerland.

Hirsch, A., Fang, Y., Asad, S., and Kapulnik, Y. 1997. The role of phytohormones in plant-microbe symbioses. Plant Soil 194:171-184.

Imsande, J., and Touraine, B. 1994. N demand and the regulation of nitrate uptake. Plant Physiol. 105:3-7.

Kaiser, B. N., Finnegan, P. M., Tyerman, S. D., Whitehead, L. F., Bergersen, F. J., Day, D. A., and Udvardi, M. K. 1998. Characterization of an ammonium transport protein from the peribacteroid membrane of soybean nodules. Science 281:1202-1206.

Lapointe, B. E. 1987. Phosphorus- and nitrogen-limited photosynthesis and growth of Gracilaria tikvahiae (Rhodophyceae) in the Florida Keys: An experimental field study. Mar. Biol. 93:561-568.

Laureano-Marín, A. M., Moreno, I., Romero, L. C., and Gotor, C. 2016. Negative regulation of autophagy by sulfide is independent of reactive oxygen species. Plant Physiol. 171:1378-1391.

Leach, J., Keyster, M., Du Plessis, M., and Ludidi, N. 2010. Nitric oxide synthase activity is required for development of functional nodules in soybean. J. Plant Physiol. 167:1584-1591.

Lee, S. G., Krishnan, H. B., and Jez, J. M. 2014. Structural basis for regulation of rhizobial nodulation and symbiosis gene expression by the regulatory protein NolR. Proc. Natl. Acad. Sci. U.S.A. 111: 6509-6514.

Li, J., Ou-Lee, T. M., Raba, R., Amundson, R. G., and Last, R. L. 1993. Arabidopsis flavonoid mutants are hypersensitive to UV-B irradiation. Plant Cell 5:171-179.

Li, L., Rose, P., and Moore, P. K. 2011. Hydrogen sulfide and cell signaling. Annu. Rev. Pharmacol. Toxicol. 51:169-187.

Li, L., Wang, Y., and Shen, W. 2012. Roles of hydrogen sulfide and nitric oxide in the alleviation of cadmium-induced oxidative damage in alfalfa seedling roots. Biometals 25:617-631.
Li, Z. G., Gong, M., Xie, H., Yang, L., and Li, J. 2012. Hydrogen sulfide donor sodium hydrosulfide-induced heat tolerance in tobacco (Nicotiana tabacum L) suspension cultured cells and involvement of $\mathrm{Ca}\left({ }^{2+}\right)$ and calmodulin. Plant Sci. 185-186:185-189.

Li, Z. G., Yang, S. Z., Long, W. B., Yang, G. X., and Shen, Z. Z. 2013. Hydrogen sulphide may be a novel downstream signal molecule in nitric oxide-induced heat tolerance of maize (Zea mays L.) seedlings. Plant Cell Environ. 36:1564-1572.

Lin, V. S., Lippert, A. R., and Chang, C. J. 2013. Cell-trappable fluorescent probes for endogenous hydrogen sulfide signaling and imaging $\mathrm{H}_{2} \mathrm{O}_{2}$-dependent $\mathrm{H}_{2} \mathrm{~S}$ production. Proc. Natl. Acad. Sci. U.S.A. 110:7131-7135.

Lin, Y. T., Li, M. Y., Cui, W. T., Lu, W., and Shen, W. B. 2012. Haem oxygenase-1 is involved in hydrogen sulfide-induced cucumber adventitious root formation. J. Plant Growth Regul. 31:519-528.

Machado D., Krishnan H.B. 2003. nodD Alleles of Sinorhizobium fredii USDA191 differentially influence soybean nodulation, nodC expression, and production of exopolysaccharides. Curr. Microbiol. 47:0134-0137.

Madsen, L. H., Tirichine, L., Jurkiewicz, A., Sullivan, J. T., Heckmann, A. B., Bek, A. S., Ronson, C. W., James, E. K., and Stougaard, J. 2010. The molecular network governing nodule organogenesis and infection in the model legume Lotus japonicus. Nat. Commun. 1: Article 10.

Marino, D., Damiani, I., Gucciardo, S., Mijangos, I., Pauly, N., and Puppo, A. 2013. Inhibition of nitrogen fixation in symbiotic Medicago truncatula upon $\mathrm{Cd}$ exposure is a local process involving leghaemoglobin. J. Exp. Bot. 64:5651-5660.

Masclaux-Daubresse, C., Daniel-Vedele, F., Dechorgnat, J., Chardon, F., Gaufichon, L., and Suzuki, A. 2010. Nitrogen uptake, assimilation and remobilization in plants: Challenges for sustainable and productive agriculture. Ann. Bot. 105:1141-1157.

Meilhoc, E., Cam, Y., Skapski, A., and Bruand, C. 2010. The response to nitric oxide of the nitrogen-fixing symbiont Sinorhizobium meliloti. Mol. Plant-Microbe Interact. 23:748-759.

Mergaert, P., Uchiumi, T., Alunni, B., Evanno, G., Cheron, A., Catrice, O., Mausset, A.-E., Barloy-Hubler, F., Galibert, F., Kondorosi, A., and Kondorosi, E. 2006. Eukaryotic control on bacterial cell cycle and differentiation in the rhizobium-legume symbiosis. Proc. Natl. Acad. Sci. U.S.A. 103:5230-5235.

Moran, N. A. 2006. Symbiosis. Curr. Biol. 16:R866-R871.

Nishikawa, F., Endo, T., Shimada, T., Fujii, H., Shimizu, T., and Omura, M. 2008. Isolation and characterization of a Citrus FT/TFL1 homologue (CuMFT1), which shows quantitatively preferential expression in Citrus seeds. J. Jpn. Soc. Hortic. Sci. 77:38-46.

Oldroyd, G. E. 2013. Speak, friend, and enter: Signalling systems that promote beneficial symbiotic associations in plants. Nat. Rev. Microbiol. 11:252-263.

Papanatsiou, M., Scuffi, D., Blatt, M. R., and García-Mata, C. 2015. Hydrogen sulfide regulates inward-rectifying $\mathrm{K}^{+}$channels in conjunction with stomatal closure. Plant Physiol. 168:29-35.

Pii, Y., Crimi, M., Cremonese, G., Spena, A., and Pandolfini, T. 2007. Auxin and nitric oxide control indeterminate nodule formation. BMC Plant Biol. 7:21.

Puppo, A., Pauly, N., Boscari, A., Mandon, K., and Brouquisse, R. 2013. Hydrogen peroxide and nitric oxide: Key regulators of the legumerhizobium and mycorrhizal symbioses. Antioxid. Redox Signal. 18: 2202-2219.

Romero, L. C., Aroca, M. Á., Laureano-Marín, A. M., Moreno, I., García, I., and Gotor, C. 2014. Cysteine and cysteine-related signaling pathways in Arabidopsis thaliana. Mol. Plant 7:264-276.

Roth, L. E., Nguyen, J. C., and Tezcan, F. A. 2010. ATP- and iron-proteinindependent activation of nitrogenase catalysis by light. J. Am. Chem. Soc. 132:13672-13674.

Schijlen, E. G., de Vos, C. H., Martens, S., Jonker, H. H., Rosin, F. M., Molthoff, J. W., Tikunov, Y. M., Angenent, G. C., van Tunen, A. J., and Bovy, A. G. 2007. RNA interference silencing of chalcone synthase, the first step in the flavonoid biosynthesis pathway, leads to parthenocarpic tomato fruits. Plant Physiol. 144:1520-1530.

Scuffi, D., Álvarez, C., Laspina, N., Gotor, C., Lamattina, L., and GarcíaMata, C. 2014. Hydrogen sulfide generated by L-cysteine desulfhydrase acts upstream of nitric oxide to modulate abscisic acid-dependent stomatal closure. Plant Physiol. 166:2065-2076.

Shen, J., Xing, T., Yuan, H., Liu, Z., Jin, Z., Zhang, L., and Pei, Y. 2013. Hydrogen sulfide improves drought tolerance in Arabidopsis thaliana by microRNA expressions. PLoS One 8:e77047.

Shi, H., Ye, T., and Chan, Z. 2013. Exogenous application of hydrogen sulfide donor sodium hydrosulfide enhanced multiple abiotic stress tolerance in bermudagrass (Cynodon dactylon (L). Pers.). Plant Physiol. Biochem. 71:226-234. 
Sun, J., Wang, R., Zhang, X., Yu, Y., Zhao, R., Li, Z., and Chen, S. 2013. Hydrogen sulfide alleviates cadmium toxicity through regulations of cadmium transport across the plasma and vacuolar membranes in Populus euphratica cells. Plant Physiol. Biochem. 65:67-74.

Tamizhselvi, R., Moore, P. K., and Bhatia, M. 2007. Hydrogen sulfide acts as a mediator of inflammation in acute pancreatitis: In vitro studies using isolated mouse pancreatic acinar cells. J. Cell. Mol. Med. 11:315-326.

Tian, H., Lu, C., Melillo, J., Ren, W., Huang, Y., Xu, X., Liu, M., Zhang, C., Chen, G., and Pan, S. 2012. Food benefit and climate warming potential of nitrogen fertilizer uses in China. Environ. Res. Lett. 7:044020.

Tilman, D., Cassman, K. G., Matson, P. A., Naylor, R., and Polasky, S. 2002. Agricultural sustainability and intensive production practices. Nature 418:671-677.

van Noorden, G. E., Ross, J. J., Reid, J. B., Rolfe, B. G., and Mathesius, U. 2006. Defective long-distance auxin transport regulation in the Medicago truncatula super numeric nodules mutant. Plant Physiol. 140: 1494-1502.

Vernié, T., Kim, J., Frances, L., Ding, Y., Sun, J., Guan, D., Niebel, A., Gifford, M. L., de Carvalho-Niebel, F., and Oldroyd, G. E. 2015. The NIN transcription factor coordinates diverse nodulation programs in different tissues of the Medicago truncatula root. Plant Cell 27:3410-3424.

Wang, B. L., Shi, L., Li, Y. X., and Zhang, W. H. 2010. Boron toxicity is alleviated by hydrogen sulfide in cucumber (Cucumis sativus L.) seedlings. Planta 231:1301-1309.

Wang, M. J., Cai, W. J., Li, N., Ding, Y. J., Chen, Y., and Zhu, Y. C. 2010. The hydrogen sulfide donor NaHS promotes angiogenesis in a rat model of hind limb ischemia. Antioxid. Redox Signal. 12:1065-1077.
Wang, Y., Wang, L., Zou, Y., Chen, L., Cai, Z., Zhang, S.., Zhao, F., Tian, Y., Jiang, Q., and Ferguson, B. J. 2014. Soybean miR172c targets the repressive $A P 2$ transcription factor $N N C 1$ to activate ENOD40 expression and regulate nodule initiation. Plant Cell 26: 4782-4801.

Werner, G. D., Cornwell, W. K., Cornelissen, J. H., and Kiers, E. T. 2015. Evolutionary signals of symbiotic persistence in the legume-rhizobia mutualism. Proc. Natl. Acad. Sci. U.S.A. 112:10262-10269.

Xu, G. H., Wolf, S., and Kafkafi, U. 2001. Effect of varying nitrogen form and concentration during growing season on sweet pepper flowering and fruit yield. J. Plant Nutr. 24:1099-1116.

Zhang, H., Hu, L. Y., Hu, K. D., He, Y. D., Wang, S. H., and Luo, J. P. 2008. Hydrogen sulfide promotes wheat seed germination and alleviates oxidative damage against copper stress. J. Integr. Plant Biol. 50: 1518-1529.

Zhang, H., Hu, S. L., Zhang, Z. J., Hu, L. Y., Jiang, C. X., Wei, Z. J., Liu, J., Wang, H. L., and Jiang, S. T. 2011. Hydrogen sulfide acts as a regulator of flower senescence in plants. Postharvest Biol. Technol. 60: 251-257.

Zhang, H., Jiao, H., Jiang, C. X., Wang, S. H., Wei, Z. J., Luo, J. P., and Jones, R. L. 2010. Hydrogen sulfide protects soybean seedlings against drought-induced oxidative stress. Acta Physiol. Plant. 32: 849-857.

Zhang, H., Tang, J., Liu, X. P., Wang, Y., Yu, W., Peng, W. Y., Fang, F., Ma, D. F., Wei, Z. J., and Hu, L. Y. 2009. Hydrogen sulfide promotes root organogenesis in Ipomoea batatas, Salix matsudana and Glycine max. J. Integr. Plant Biol. 51:1086-1094. 